\title{
Performance Characterisation of a Hybrid Flat-Plate Vacuum Insulated Photovoltaic/Thermal Solar Power Module in Subtropical Climate
}

\author{
Andrew Y. A. Oyieke and Freddie L. Inambao \\ Discipline of Mechanical Engineering, University of KwaZulu-Natal, Durban 4041, South Africa \\ Correspondence should be addressed to Andrew Y. A. Oyieke; youngoyieke@yahoo.com
}

Received 27 April 2016; Revised 13 July 2016; Accepted 18 July 2016

Academic Editor: Diego A. L. García

Copyright (C) 2016 A. Y. A. Oyieke and F. L. Inambao. This is an open access article distributed under the Creative Commons Attribution License, which permits unrestricted use, distribution, and reproduction in any medium, provided the original work is properly cited.

\begin{abstract}
A flat-plate Vacuum Insulated Photovoltaic and Thermal (VIPV/T) system has been thermodynamically simulated and experimentally evaluated to assess the thermal and electrical performance as well as energy conversion efficiencies under a subtropical climate. A simulation model made of specified components is developed in Transient Systems (TRNSYS) environment into which numerical energy balance equations are implemented. The influence of vacuum insulation on the system's electrical and thermal yields has been evaluated using temperatures, current, voltage, and power flows over daily and annual cycles under local meteorological conditions. The results from an experiment conducted under steady-state conditions in Durban, South Africa, are compared with the simulation based on the actual daily weather data. The VIPV/T has shown improved overall and thermal efficiencies of $9.5 \%$ and $16.8 \%$, respectively, while electrical efficiency marginally reduced by $0.02 \%$ compared to the conventional PV/T. The simulated annual overall efficiency of $29 \%$ (i.e., $18 \%$ thermal and $11 \%$ electrical) has been realised, in addition to the solar fraction, overall exergy, and primary energy saving efficiencies of $39 \%, 29 \%$, and $27 \%$, respectively.
\end{abstract}

\section{Introduction}

Considering the enormous amount of untapped renewable energy resources worldwide, the technical, economic, and market potentials for solar energy harnessing systems are still far below the theoretical potential due to their diffuse and intermittent nature. The main challenge is how to move to more efficient power generation and conversion systems, while at the same time continuing to extend affordable access. Hybrid photovoltaic/thermal (PV/T) systems have emerged as economic and efficient state of the art technologies for solar energy conversion into both electrical and thermal (heat) energy simultaneously within the same unit. They provide effective and convenient means of maximizing total energy output per unit areas compared to individual thermal and PV modules mounted side by side [1]. However, in their current states, electrical energy generation is prioritized in hybrid $\mathrm{PV} / \mathrm{T}$ systems, while thermal energy output is relegated to an electrical efficiency improvement mechanism. Hence, they operate at comparatively lower thermal efficiencies compared to individual solar thermal collectors inhibiting their competitiveness and application. Since silicon PV cells are limited to an electrical efficiency between $15 \%$ and $20 \%$ [2], any attempt to improve the PV/T systems' overall efficiency must focus on the thermal output.

Considerable gains have been recorded in hybrid PV/T technology with regard to overall system efficiency improvement in the recent past. These studies are related but not limited to the performance evaluation of different types of $\mathrm{PV} / \mathrm{T}$ configurations, geometrical optimization, and operational parameters associated with the PV/T $[3,4]$. Experimental, simulation, and modelling studies using different techniques, software and simulation tools, have resulted in various useful outcomes [1,5-11]. Numerous theories and computer based thermal models have been proposed [12, 13], analytical expressions and characteristic equations were derived [14], and design configurations were suggested and simulation results were obtained $[4,15]$. Validation studies 
by comparison between simulated and experimental data for error analysis have given insights into the extent of accuracy of simulated results [16-18].

The present study investigates the vacuum insulation as thermal efficiency improvement technique in a flat-plate hybrid PV/T system without compromising electrical efficiency to increase its competitiveness with the individual thermal units. A graphical simulation model with special temperature controls is developed in TRNSYS program into which detailed numerical data are entered to accurately evaluate the functional properties of the Vacuum Insulated Hybrid Photovoltaic and Thermal (VIPV/T) system. The influence of vacuum insulation on the electrical and thermal performance of the PV/T system using temperatures and power flow over medium-term duration (daily cycle) is done based on the model developed. To check the functionality, validity, and accuracy of the model, the results are compared with those of an outdoor experiment conducted on the hybrid VIPV/T and conventional air-insulated $\mathrm{PV} / \mathrm{T}$ subjected to the same weather conditions and input parameters.

The experimental set-up is presented in Section 2, describing the procedures, materials, and equipment. Section 3 presents the system's model developed in TRNSYS environment, giving details of individual component types and numerical energy balance equations. The simulation procedure is covered in Section 4, and simulation results are discussed in terms of energy yields and efficiencies in Section 5. Section 6 deals with validation of simulation results with experimental data, and finally the relevant conclusions are drawn in Section 7.

\section{Experimental Set-Up}

The materials and equipment used in the experiment were as follows: water storage tank, battery, charge controller, water circulation pump, data logger, thermocouples, and multimeter. A conventional PVT collector with air gap was used as a control, installed side by side, and connected in parallel with the VIPVT collector ensuring their outlets discharge to the tank in complete independence on each other. The whole assembly was subjected to same weather input parameters such as solar irradiance, wind speed, and air temperature measured and recorded on site. The various components were assembled onto a mobile support frame for mobility and easy positional adjustment. The angle of inclination was fixed at optimum level of $35^{\circ}$ adopted from the previous simulation study by [19]. The plumbing works were done using $22 \mathrm{~mm}$ copper tubes and associated fittings with the hot water side lagged to reduce heat losses to the environment. The water storage tank was laid horizontally for ease of water draw and stability of support structure.

The solar irradiance was measured using a thermopile SPN1 pyranometer having a sensitivity factor of 0.1 , while wind speed and air temperature were measured using R M Young and Campbell scientific sensors, respectively, with accuracies of \pm 0.1 each. The PV cell average temperature was measured using 5 surface mounted Type-E thermocouple sensors distributed evenly on the surface of the panel whose readings were simultaneously logged and averaged. The water temperatures at the inlets and outlets of the modules were measured by use of type-K thermocouples and logged onto the DataTaker DT80 and then transferred to the computer for storage and further analysis at the end of each day. The electrical terminals were connected to the charge controller, enabling currents and voltages from each panel to be measured and logged separately. The charge controller was installed and configured with an algorithm to charge and monitor the state of charge of the regulated valve lead acid deep cycle battery. A $300 \mathrm{~W}$ inverter was connected to the battery to convert DC to AC and supply power to the loads which would discharge the battery in readiness for another charge cycle.

In order to attain considerable difference in temperatures, the measurements were configured to be logged at intervals of 15 minutes, a time step that was good enough for solar energy to make considerable change in temperatures. For voltages and currents, this interval was insignificant, since they varied in the order of milliseconds but were logged at the same instances with the temperatures for assessment of efficiencies. Measurements of current, voltage, and temperatures (inlet, outlet, collector surface, and tank) at specified regular intervals during the sunshine hours enabled determination of electrical power output, thermal output, and correlation of effect of vacuum insulation. The results were further processed and used as benchmark for simulation. The pictorial representations of the front and rear views of the set-up are as shown in Figure 1.

\section{The TRNSYS Model of the PV/T System}

The system model is developed using predefined individual component models with preformulated properties and userspecified/modified numerical characterisation in Transient Systems Simulation (TRNSYS) software. The program was chosen because it consists of subroutines that model subsystems. The basic hybrid PV/T system is represented by a TRNSYS model comprised of a combination of several components interlinked together by lines and arrows depicting the process and information flows. Each component is associated with a specific task and a combined effect of the components accomplishes the intended larger task of the whole system. For each connection, there are accurately defined inputs, inbuilt parameters activated to influence the behaviour of a component in a desired manner, and the expected outputs.

The flexibility of the model allows for change of component parameters like the manufacturer's geometric and operational specifications to simulate expected performances subject to the prevailing meteorological conditions. By altering the weather characteristics of the intended geographical location of installation and the geometrical dimensions of the $\mathrm{PV} / \mathrm{T}$ collector module, the model is capable of giving out the results of thermal and electrical performance. Although the loads may vary, flexibility in alteration of the various schedules as per location is also provided. The user has the option of altering the desired outputs to be plotted, but basically the most critical ones have been included in this 


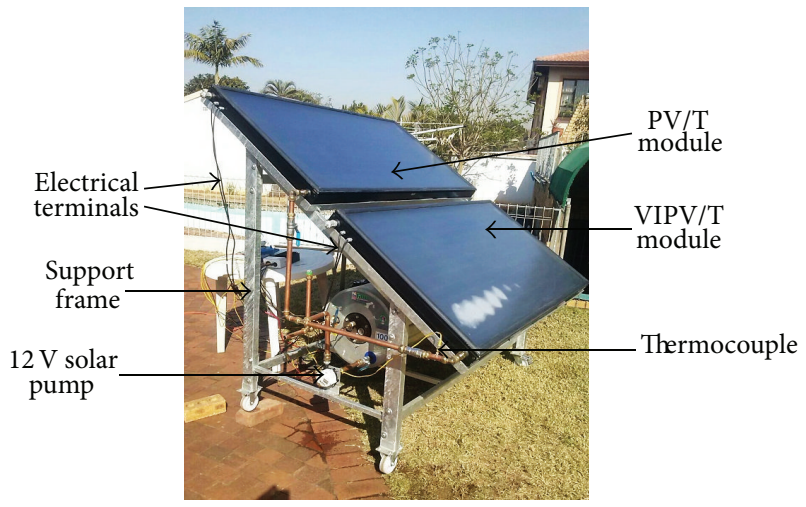

(a) Front view

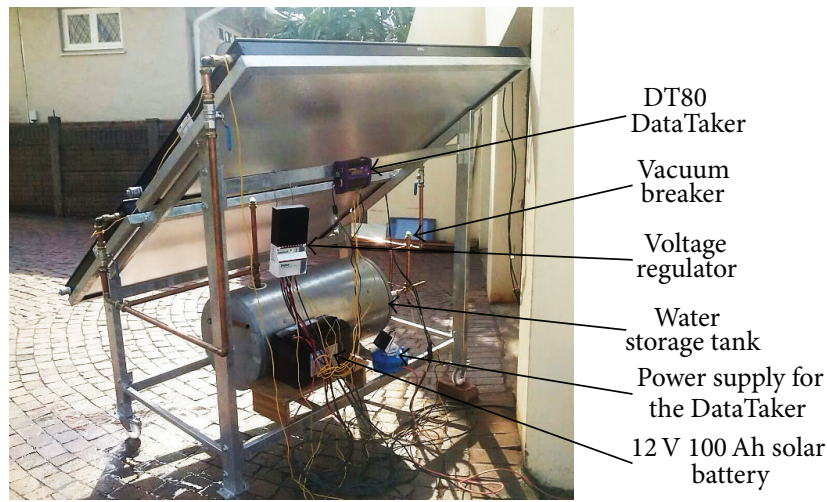

(b) Rear view

FIgURE 1: The experimental set-up assembly

model. The graphical representation of the model is shown in Figure 2.

3.1. General System Description of the PV/T Model. Pumped circulation system is preferred for this study because of its flexibility in location of the storage tank and improved aesthetics of the system. The water loop/thermal side of the model is somewhat contrived, with the solar pump circulating cold water from the storage tank to the VIPV/T or $\mathrm{PV} / \mathrm{T}$ collector array where it is heated. Hot water then leaves the collector into the tank for storage and further to the hot water loads. The ON/OFF differential controller senses the set lower and higher limits of VIPV/T or PV/T temperatures and triggers the solar pump accordingly. The controller also causes the tank to be emptied through the flow mixer by a predefined load and is refilled by make-up water when it reaches a low volume limit. The storage tank is equipped with an auxiliary heater that carries the heating load when there is no sunshine. The electrical power output from the VIPV/T or $\mathrm{PV} / \mathrm{T}$ array is passed through the inverter/charge controller which compares it with a predefined electrical loads. The charge controller, depending on its settings, then determines whether the electrical generation should be used to meet the load or charge the battery.

A summary of the components used in the model is presented in the Table 1. These components are selected from the inbuilt TESS library and tested for compatibility by comparing individual inputs, parameters, and expected outputs with respect to the proceeding counterparts before implementing them into the model.

\subsection{Individual Component Models}

3.2.1. VIPV/T and $P V / T$ Collector Model. The structural configuration of the PV/T collector typically comprises a PV module mounted on a heat sensitive material known as the absorber whose principal function is to conduct away the heat absorbed by the PV cells to a circulating heat removal fluid. Ducts or tubes are provided either under or above the absorber plate to provide passage for the fluid, depending on the configuration [15]. In the water based PV/T, sheet and tube configuration is the most commonly used, reliable,
TABLE 1: TRNSYS model components.

\begin{tabular}{lcc}
\hline Model part & Component & TRNSYS types \\
\hline $\begin{array}{l}\text { Main } \\
\text { components }\end{array}$ & PV/T collector & Type 50d \\
& Weather generator & Type 15-2 \\
\hline & Storage tank & Type 4c \\
& ON/OFF differential controller & Type 2b \\
Thermal loop & Pump & Type 3b \\
& Flow diverter & Type 11b \\
& Flow mixer & Type 11h \\
\hline Electrical & Battery & Type 47 \\
loop & Voltage regulator/inverter & Type 2b \\
\hline \multirow{2}{*}{$\begin{array}{l}\text { Utility and } \\
\text { output }\end{array}$} & On-line plotter & Type 65c \\
devices & Printer & Type 25c \\
& Integrator & Type 24 \\
\hline
\end{tabular}

cheap to construct, and most promising notwithstanding its slightly lower efficiency compared to other configurations. The collector may also be glazed (glass covered) or unglazed. The former has been shown to attain the highest thermal efficiency compared to the latter and has been recommended for domestic sanitary water applications [4]. For the purpose of this study, the application is in the domestic domain; hence the glazed, sheet and tube design was chosen for simulation.

The modified conventional PV/T collector to include a vacuum envelop between the glazing and PV cells constitutes a VIPV/T collector. Both the PV/T and VIPV/T are simulated as hybrid collectors that combine both the analysis and operation of flat-plate collectors functioning at peak power and $I-V$ curves of the PV cells (or array) to solve for peak power with current output at some forced voltage. Consideration of energy loss as a function of temperatures, wind speeds, solar radiation and collector angle gives rise to parameters which are easily defined in the input file. Since the VIPV/T collector is the main subject of this study, it is modelled with modified heat loss characteristics due to the vacuum insulation on the top part of the module 


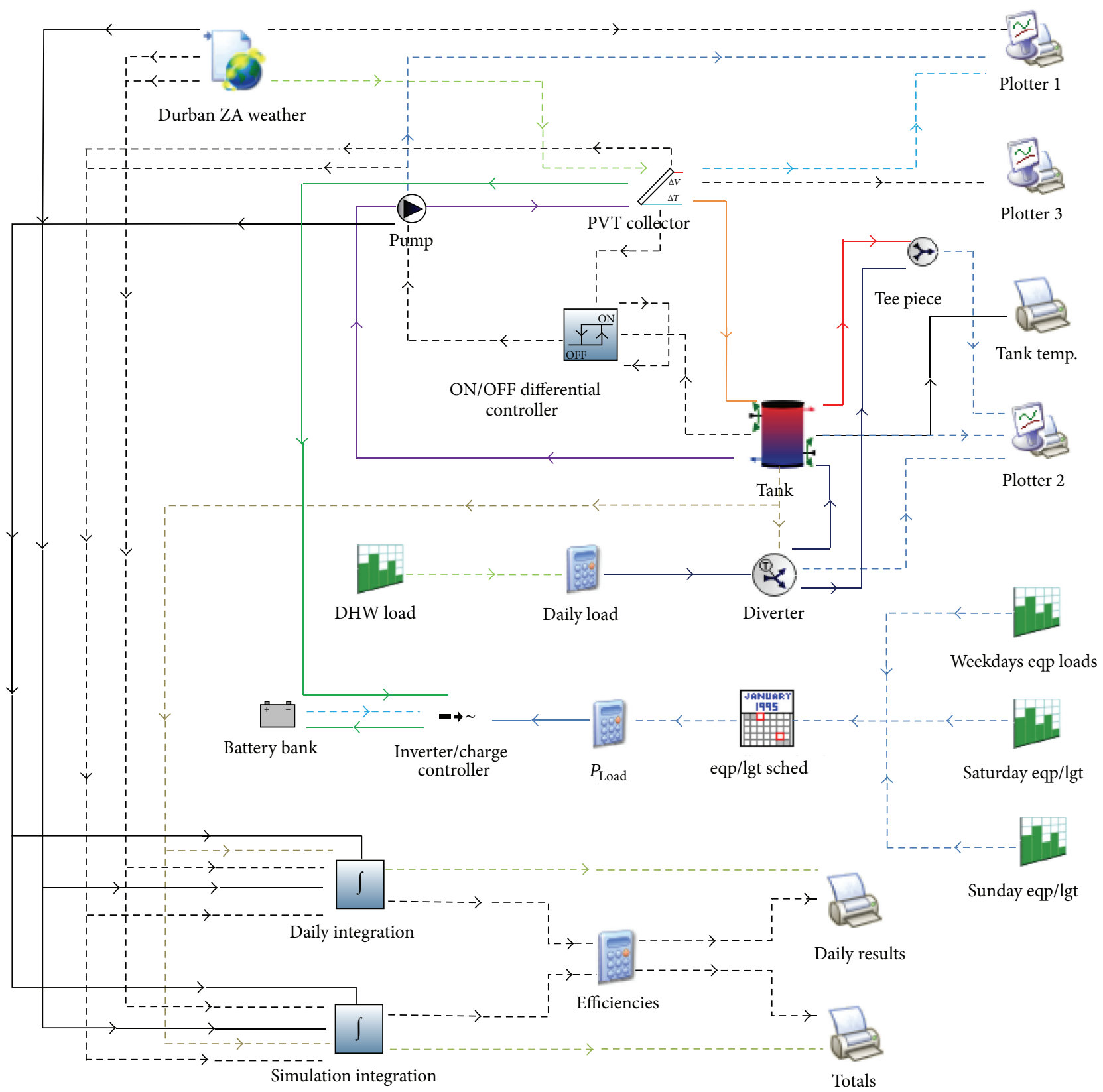

FIGURE 2: The TRNSYS graphical model of VIPV/T system.

between the PV cells and the glazing. These modifications are made to encompass the radiative, convective, and conductive heat flow characteristics. The technical specifications of the modules used are summarized in Table 2.

3.2.2. The Energy Balance Models. Unidimensional models achieve acceptable level of precision compared to the multifaceted ones when calculating the energy balance [20]. In this regard, a transient model can be developed by upholding the principle of conservation of energy on each of the individual layers of the collector as seen in [1]. Based on this technique, the energy balance is formulated for both PV/T and VIPV/T modules, the results of which are sets of nonlinear transient first-order differential equations. The cross sections of both $\mathrm{PV} / \mathrm{T}$ and VIPV/T are shown in Figure 3, demonstrating the heat flows across the respective layers. It is worth noting that the conventional $\mathrm{PV} / \mathrm{T}$ has additional glass encapsulation for the PV cells which is absent in the VIPV/T module under consideration. The thermophysical properties and parameters used in the model are tabulated in Table 3.

The Energy Balance Model for PV/T. For the single glazed $\mathrm{PV} / \mathrm{T}$ collector with glass-encapsulated PV cells, the heat flow equations are formulated from Figure 3(a) in terms of heat fluxes as follows.

The heat flux on the surface of the module top glazing $\dot{q}_{1}$ is a combination of heat loss due to radiation and effects of wind, given by

$$
\dot{q}_{1}=\dot{q}_{1, \mathrm{rad}}+\dot{q}_{1, \text { wind }} .
$$




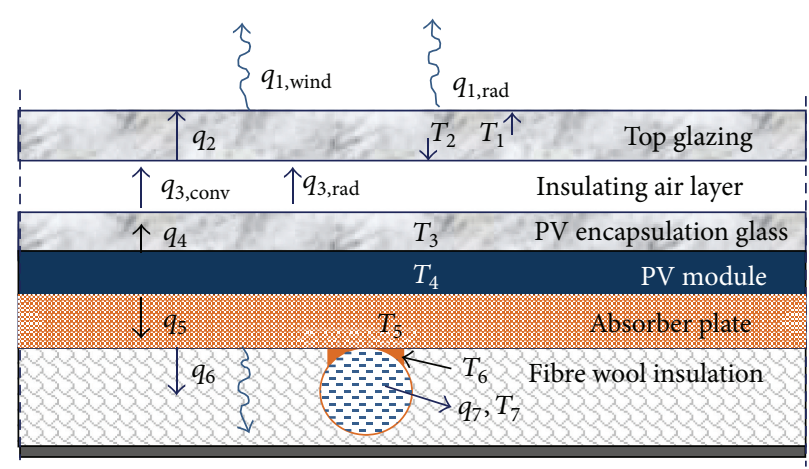

(a) Conventional air-insulated PV/T

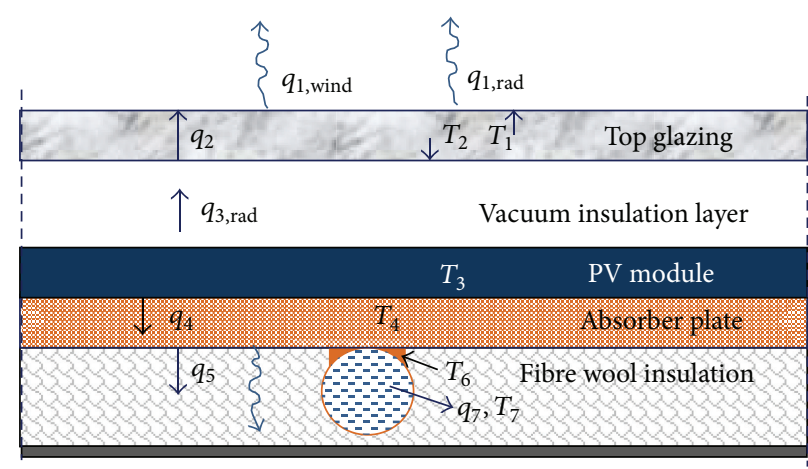

(b) Vacuum insulated PV/T

FIgURE 3: The heat flow and temperature distribution diagrams for PV/T and VIPV/T modules.

TABLE 2: VIP/T and PV/T collector specifications.

\begin{tabular}{lcc}
\hline Collector property & VIP/T & PV/T \\
\hline Collector area & $1.42 \mathrm{~m}^{2}$ & $1.42 \mathrm{~m}^{2}$ \\
Collector slope & $35^{\circ}$ & $35^{\circ}$ \\
Absorber type & Sheet and tube & Sheet and tube \\
Plate thickness & $0.001 \mathrm{~m}$ & $0.001 \mathrm{~m}$ \\
Plate material & Copper & Copper \\
Internal piping & Copper & Copper \\
Riser tube dia. & $0.012 \mathrm{~m}$ & $012 \mathrm{~m}$ \\
Header tube diameter & $0.022 \mathrm{~m}$ & $022 \mathrm{~m}$ \\
Tube spacing & 120 & 120 \\
Plate-tube attachment & Welding & Welding \\
Module power & $180 \mathrm{~W}$ & $180 \mathrm{~W}$ \\
PV cell type & Monocrystalline & Monocrystalline \\
PV cell area & $0.0156 \mathrm{~m}^{2}$ & $0.0156 \mathrm{~m}^{2}$ \\
Number of cells & 72 & 72 \\
PV cell encapsulation & Nonencapsulated & Encapsulated \\
Top insulation & Vacuum & Air \\
Bottom insulation & Fibre wool & Fibre wool \\
Insulation thickness & $0.05 \mathrm{~m}$ & $0.05 \mathrm{~m}$ \\
Glass cover & $0.004 \mathrm{~m}$ low iron & $0.004 \mathrm{~m}$ low iron \\
PV glass thickness & tempered & tempered \\
\hline
\end{tabular}

The radiative heat flux form the top glazing surface due to effect of sky radiation $\dot{q}_{1, \text { rad }}$ is given as

$$
\dot{q}_{1, \text { rad }}=F_{\text {sky }} \varepsilon_{g} \sigma\left(T_{1}^{4}-T_{\text {sky }}^{4}\right)+F_{\text {grd }} \varepsilon_{g} \sigma\left(T_{1}^{4}-T_{a}^{4}\right),
$$

where

$$
\begin{aligned}
& T_{\text {sky }}=T_{a}\left[0.711+0.056 T_{\mathrm{dp}}+0.000073 T_{\mathrm{dp}}^{2}\right. \\
& \quad+0.013 \cos (15 t)]^{0.25} .
\end{aligned}
$$

$T_{\mathrm{dp}}$ and $T_{a}$ are dew point and ambient temperatures, respectively, obtained from experimental measurements and $t$ time in hours counted from midnight [21].
TABLE 3: Parameters used in the analysis.

\begin{tabular}{lc}
\hline Parameter & Value \\
\hline Emissivity of cover glass & 0.9 \\
Emissivity of PV cells & 0.9 \\
Thermal conductivity of glass & $0.9 \mathrm{~W} / \mathrm{mK}$ \\
Width of air gap & $50 \mathrm{~mm}$ \\
Width of vacuum cavity & $75 \mathrm{~mm}$ \\
Thermal conductivity of air & $0.025 \mathrm{~W} / \mathrm{mK}$ \\
Thermal conductivity of vacuum & $0.004 \mathrm{~W} / \mathrm{mK}$ \\
Thermal conductivity of back insulation & $1 \mathrm{~W} / \mathrm{m}^{2} \mathrm{~K}$ \\
layer & $385 \mathrm{~W} / \mathrm{m}^{2} \mathrm{~K}$ \\
Thermal conductivity of copper & $4.2 \mathrm{~kJ} / \mathrm{kgK}$ \\
Heat capacity of water & $10 \mathrm{~kg} / \mathrm{m}^{2} \mathrm{~h}$ \\
Water flow rate & $125 \mathrm{~W} / \mathrm{m}^{2} \mathrm{~K}$ \\
Heat transfer from PV cell to absorber plate & $100 \mathrm{l}$ \\
Volume of water storage tank & $1 \mathrm{~W} / \mathrm{K}$ \\
Heat loss from the storage tank & $2.69 \times 10^{-5}\left(\mathrm{~m} / \mathrm{s}^{2}\right)$ \\
Thermal diffusivity of air & $1.88 \times 10^{-5}\left(\mathrm{~m} / \mathrm{s}^{2}\right)$ \\
Kinematic viscosity of air &
\end{tabular}

The heat flux from the top glazing surface due to effect of sky radiation carried away by wind $\dot{q}_{1 \text {,wind }}$ is given as

$$
\dot{q}_{1, \text { wind }}=\frac{\mathrm{Nu}_{\mathrm{wind}} k_{\mathrm{air}}}{l_{c}}\left(T_{1}-T_{a}\right) \text {, }
$$

where

$$
\begin{aligned}
\mathrm{Nu}_{\text {wind }}= & 0.56\left(\mathrm{Ra}_{\mathrm{cr}} \sin \beta\right)^{0.25} \\
& +0.13\left(\mathrm{Ra}^{0.333}-\mathrm{Ra}_{\mathrm{cr}}^{0.333}\right), \\
\mathrm{Ra}= & \frac{\operatorname{Pr}\left(g \beta\left(T_{1}-T_{a}\right) l_{c}^{3}\right)}{v^{2}},
\end{aligned}
$$

where $\mathrm{Ra}_{\mathrm{cr}}=10^{8}$ and $\operatorname{Pr}=\omega / v$. The heat flux across the top glazing $\dot{q}_{2}$ is given as

$$
\dot{q}_{2}=\dot{q}_{3, \text { rad }}+\dot{q}_{3, \text { conv }}-\dot{q}_{1, \text { rad }}-\dot{q}_{1, \text { wind }}+\frac{k_{g}}{\delta_{T g}}\left(T_{2}-T_{1}\right) .
$$


The heat flux across the insulating air layer $\dot{q}_{3}$ is the sum of the convective $\dot{q}_{3, \text { conv }}$ and radiative $\dot{q}_{3 \text {, rad }}$ components expressed as

$$
\dot{q}_{3}=\dot{q}_{3, \mathrm{conv}}+\dot{q}_{3, \mathrm{rad}}-\dot{q}_{2}+\dot{q}_{4} .
$$

The radiative heat flux across $\dot{q}_{3 \text {,rad }}$ is given as

$$
\dot{q}_{3, \mathrm{rad}}=\frac{\varepsilon_{g} \varepsilon_{\mathrm{pv}}}{\varepsilon_{g}+\varepsilon_{\mathrm{pv}}-\varepsilon_{g} \varepsilon_{\mathrm{pv}}} \sigma\left(T_{3}^{4}-T_{2}^{4}\right) .
$$

The convective heat flux across the insulating air layer $\dot{q}_{3 \text {,conv }}$ is determined as

$$
\dot{q}_{3, \mathrm{conv}}=\frac{\mathrm{Nu}_{\mathrm{air}} k_{\mathrm{air}}}{l_{\mathrm{ins}}}\left(T_{3}-T_{2}\right),
$$

where

$$
\begin{aligned}
& \mathrm{Nu}_{\text {air }} \\
& =1 \\
& \quad+1.44\left[1-\frac{1708(\sin 1.8 \beta)^{1.6}}{\mathrm{Ra} \cos \beta}\right]\left[1-\frac{1708}{\mathrm{Ra} \cos \beta}\right]^{+} \\
& \quad+\left[\left(\frac{\mathrm{Ra} \cos \beta}{1708}\right)^{0.333}-1\right]^{+} .
\end{aligned}
$$

According to [21], the terms raised to $(+)$ sign are considered only if their value is positive.

It should be noted that heat flows are in both radiative and convective modes in this layer.

The residual heat energy emitted from the PV module must all be transferred to the absorber for maximum thermal performance; thus, heat flux across the PV module $\dot{q}_{4}$ is given as

$$
\dot{q}_{4}=\frac{k_{g}}{\delta_{\text {pvg }}}\left(T_{4}-T_{3}\right)-\dot{q}_{3} .
$$

The heat flux across the absorber $\dot{q}_{5}$ is given as

$$
\dot{q}_{5}=\left(\tau \alpha-\tau_{\mathrm{pv}} \eta_{\mathrm{el}}\right) G-\dot{q}_{4}-h_{5}\left(T_{4}-T_{5}\right) .
$$

Since, the PV module is attached to the absorber plate using a thin and highly conductive adhesive layer of Tedlar, Ethyl Vinyl Acetate (EVA), and glue successively. The respective thermal conductivity $(k)$ values adopted for this study are $0.2 \mathrm{~W} / \mathrm{mK}, 0.35 \mathrm{~W} / \mathrm{mK}$, and $0.85 \mathrm{~W} / \mathrm{mK}$, and thickness $(\delta)$ is $0.1 \mathrm{~mm}, 0.5 \mathrm{~mm}$, and $50 \mu \mathrm{m}$, respectively, to minimise thermal resistance. The combined heat transfer coefficient for the PV laminate is calculated as

$$
h_{5}=\left(R_{\mathrm{EVA}}+R_{\text {tedlar }}+R_{\text {glue }}\right)^{-1},
$$

where $R=l / k A$ with respect to each layer.

The heat flux across the absorber-tube bond $\dot{q}_{6}$ is given as

$$
\begin{aligned}
& \dot{q}_{6}=\frac{k_{\text {ins }}}{\delta_{\text {ins }}}\left(T_{\text {ins }}-T_{\text {abs }}\right)+\dot{q}_{5}, \\
& \dot{q}_{7}=\dot{q}_{6}+\frac{k_{\text {bond }}}{\delta_{\text {bond }}}\left(T_{6}-T_{7}\right)-\dot{m} C_{p}\left(T_{o}-T_{i}\right) .
\end{aligned}
$$

The heat flow between the absorber plate and PV module is modelled as follows. Using the temperature distribution schematic in Figure 3(a), Hottel-Whiller equation as given in [21] is applied to obtain $T_{\mathrm{abs}}$ as follows:

$$
\begin{aligned}
T_{\mathrm{abs}}= & T_{a}+\cosh (m) \frac{T_{b}+T_{a}-\left(\alpha \tau-\tau_{\mathrm{pv}} \eta_{\mathrm{el}}\right) G / U_{\text {loss }}}{\cosh \left[m\left(W-D_{e}\right) / 2\right]} \\
& +\frac{\left(\alpha \tau-\tau_{\mathrm{pv}} \eta_{\mathrm{el}}\right) G}{U_{\text {loss }}}
\end{aligned}
$$

where

$$
m=\left(\frac{U_{\text {loss }}}{k \delta_{\text {abs }}}\right)^{1 / 2} .
$$

The heat loss coefficient $U_{\text {loss }}$ and $T_{5}$ are expressed as

$$
\begin{aligned}
U_{\text {loss }} & =\frac{\dot{q}_{1, \mathrm{rad}}+\dot{q}_{1, \mathrm{wind}}+h_{6}\left(T_{5}-T_{\mathrm{abs}}\right)}{\left(T_{3}-T_{a}\right)}, \\
T_{5} & =\frac{T_{i}+T_{o}}{2}+\frac{\dot{m} C_{p}\left(T_{o}-T_{i}\right) D_{e}}{\mathrm{Nu}_{t} k_{w}},
\end{aligned}
$$

where $\operatorname{Re}<2300 \rightarrow \mathrm{Nu}_{t}=4.3$ and $\operatorname{Re}>2300 \rightarrow \mathrm{Nu}_{t}=$ $0.023 \operatorname{Re}^{0.8} \operatorname{Pr}^{0.4}$. obtain

Taking the energy balance for the top glass cover, we

$$
\begin{aligned}
M_{1} C_{p 1} \frac{d T_{1}}{d t}= & \frac{\mathrm{Nu}_{\mathrm{air}} k_{\text {air }}}{l_{\text {ins }}}\left(T_{3}-T_{2}\right) \\
& -F_{\text {sky }} \varepsilon_{g} \sigma\left(T_{1}^{4}-T_{\text {sky }}^{4}\right) \\
& +\frac{\varepsilon_{g} \varepsilon_{\mathrm{pv}}}{\varepsilon_{g}+\varepsilon_{\mathrm{pv}}-\varepsilon_{g} \varepsilon_{\mathrm{pv}}} \sigma\left(T_{3}^{4}-T_{2}^{4}\right) \\
& -\frac{\mathrm{Nu}_{\mathrm{wind}} k_{\mathrm{air}}}{l_{c}}\left(T_{1}-T_{a}\right) \\
& +F_{\mathrm{grd}} \varepsilon_{g} \sigma\left(T_{1}^{4}-T_{a}^{4}\right) .
\end{aligned}
$$

The energy balance to the air insulation layer is given by

$$
\begin{aligned}
M_{2} C_{p 2} \frac{d T_{2}}{d t}= & \frac{k_{g}}{\delta_{\mathrm{pvg}}}\left(T_{4}-T_{3}\right)-\frac{k_{g}}{\delta_{T g}}\left(T_{2}-T_{1}\right) \\
& -\frac{\mathrm{Nu}_{\mathrm{air}} k_{\mathrm{air}}}{l_{\mathrm{ins}}}\left(T_{3}-T_{2}\right) \\
& -\frac{\varepsilon_{g} \varepsilon_{\mathrm{pv}}}{\varepsilon_{g}+\varepsilon_{\mathrm{pv}}-\varepsilon_{g} \varepsilon_{\mathrm{pv}}} \sigma\left(T_{3}^{4}-T_{2}^{4}\right) .
\end{aligned}
$$



by

The energy balance to the PV encapsulation glass is given

$$
\begin{aligned}
M_{3} C_{p 3} \frac{d T_{3}}{d t}= & \left(\tau \alpha-\tau_{\mathrm{pv}} \eta_{\mathrm{el}}\right) G-\frac{k_{g}}{\delta_{\mathrm{pvg}}}\left(T_{4}-T_{3}\right) \\
& -\frac{\mathrm{Nu}_{\mathrm{air}} k_{\mathrm{air}}}{l_{\mathrm{ins}}}\left(T_{3}-T_{2}\right) \\
& -\frac{\varepsilon_{g} \varepsilon_{\mathrm{pv}}}{\varepsilon_{g}+\varepsilon_{\mathrm{pv}}-\varepsilon_{g} \varepsilon_{\mathrm{pv}}} \sigma\left(T_{3}^{4}-T_{2}^{4}\right) .
\end{aligned}
$$

The energy balance to the PV module is given by

$$
M_{4} C_{p 4} \frac{d T_{4}}{d t}=h_{5}\left(T_{4}-T_{5}\right)-\frac{k_{g}}{\delta_{\text {pvg }}}\left(T_{4}-T_{3}\right) .
$$

The energy balance to the absorber plate is given by

$$
\begin{aligned}
M_{5} C_{p 5} \frac{d T_{5}}{d t}= & h_{\mathrm{abs}}\left(T_{4}-T_{5}\right)-h_{b-a}\left(T_{5}-T_{a}\right) \\
& -h_{b}\left(T_{5}-T_{6}\right) .
\end{aligned}
$$

The energy balance to the absorber plate and tube joints is given by

$$
\begin{aligned}
M_{6} C_{p 6} \frac{d T_{6}}{d t}= & h_{\mathrm{abs}}\left(T_{4}-T_{5}\right)-h_{b-a}\left(T_{5}-T_{a}\right) \\
& -\dot{m} C_{p}\left(T_{o}-T_{i}\right) .
\end{aligned}
$$

Finally, the energy balance to the fluid flowing in the tubes is given by

$$
M_{7} C_{p 7} \frac{d T_{7}}{d t}=h_{b}\left(T_{6}-T_{7}\right)-\dot{m} C_{p}\left(T_{o}-T_{i}\right),
$$

where $T_{7}$ is taken to be the fluid mean temperature given by

$$
T_{7}=\frac{T_{i}+T_{o}}{2}
$$

The Energy Balance Model for VIPV/T. The thermal energy flow through the layers constituting the VIPV/T is analysed in the same manner as the PV/T. Referring to Figure 3(b), the heat flow schematics are presented enabling an energy study. The major difference between the two scenarios is that the air insulation layer has been replaced with a vacuum insulation layer and the PV glass encapsulation is removed. This option eliminates $\dot{q}_{3 \text {,conv }}$ and $\dot{q}_{4}$ terms; hence (9) and (11) do not apply. The heat flow equations are thus formulated as follows.

The heat flow to form the top glazing cover remains unchanged as expressed in (1).

Heat flux through the top glazing is given by

$$
\dot{q}_{2}=\dot{q}_{3, \text { rad }}-\dot{q}_{1, \text { rad }}-\dot{q}_{1, \text { wind }}+\frac{k_{g}}{\delta_{T g}}\left(T_{2}-T_{1}\right) .
$$

Heat flow through the vacuum insulation $\dot{q}_{3}$ is the same as given in (8).
The heat flow through the PV module to the collector plate $\dot{q}_{4}$ is formulated as

$$
\dot{q}_{4}=\left(\tau \alpha-\tau_{\mathrm{pv}} \eta_{\mathrm{el}}\right) G-q_{3, \mathrm{rad}}
$$

The heat flow between the absorber plate and PV module $\dot{q}_{4}$ and from the back of the collector to the ambient $\dot{q}_{5}$ remains as formulated in (12) and (14).

The heat transfer coefficient for the PV module to the collector $h_{4}$ is equal to $h_{5}$ as shown in (13).

The heat flow to the water inside the tube $\dot{q}_{6}$ is equivalent to $\dot{q}_{7}$ as given in (15).

Taking the energy balance for the glass cover, we obtain

$$
\begin{aligned}
M_{1} C_{p 1} \frac{d T_{1}}{d t}= & \frac{\varepsilon_{g} \varepsilon_{\mathrm{pv}}}{\varepsilon_{g}+\varepsilon_{\mathrm{pv}}-\varepsilon_{g} \varepsilon_{\mathrm{pv}}} \sigma\left(T_{3}^{4}-T_{2}^{4}\right) \\
& -F_{\mathrm{sky}} \varepsilon_{g} \sigma\left(T_{1}^{4}-T_{\mathrm{sky}}^{4}\right) \\
& -\frac{\mathrm{Nu}_{\text {wind }} k_{\mathrm{air}}}{l_{c}}\left(T_{1}-T_{a}\right) \\
& +F_{\mathrm{grd}} \varepsilon_{g} \sigma\left(T_{1}^{4}-T_{a}^{4}\right) .
\end{aligned}
$$

The energy balance to the vacuum insulation layer is formulated as

$$
\begin{aligned}
M_{2} C_{p 2} \frac{d T_{2}}{d t}= & \left(\tau \alpha-\tau_{\mathrm{pv}} \eta_{\mathrm{el}}\right) G-h_{\mathrm{pv}}\left(T_{4}-T_{3}\right) \\
& -\frac{k_{g}}{\delta_{T g}}\left(T_{2}-T_{1}\right) .
\end{aligned}
$$

The energy balance to the PV module is given by

$$
\begin{aligned}
M_{3} C_{p 3} \frac{d T_{3}}{d t}= & h_{\mathrm{pv}-c}\left(T_{3}-T_{4}\right) \\
& -\frac{\varepsilon_{g} \varepsilon_{\mathrm{pv}}}{\varepsilon_{g}+\varepsilon_{\mathrm{pv}}-\varepsilon_{g} \varepsilon_{\mathrm{pv}}} \sigma\left(T_{3}^{4}-T_{2}^{4}\right) .
\end{aligned}
$$

The energy balance to the absorber plate and platetube bond remains unchanged as given in (23) and (24), respectively. These energy equations are implemented in the simulation for both PV/T and VIPV/T.

The thermal efficiency $\eta_{\text {th }}$ of a flat-plate collector is expressed as the ratio of useful thermal energy absorbed by the collector $Q_{u}$ to the total solar irradiation $G$ calculated by

$$
\eta_{\mathrm{th}}=\frac{Q_{u}}{G}
$$

where $Q_{u}$ is expressed as the product of mass flow rate $\dot{m}$ and specific heat capacity $C_{p}$ of the cooling fluid and the temperature difference of the fluid at outlet $T_{o}$ and inlet $T_{i}$ given as

$$
Q_{u}=\dot{m} C_{p}\left(T_{o}-T_{i}\right)
$$

Electrical efficiency $\eta_{\mathrm{el}}$ of the PV panel depends majorly on the incident solar radiation and PV module temperature 
$T_{\mathrm{pv}}$. It is defined as the ratio of maximum electrical power output to the incident radiation and is inversely proportional to the temperature; that is, it is reduced when the temperature increases. To demonstrate this effect of temperature on the $\mathrm{PV}$ efficiency, an expression from [21] is adopted in this case given as

$$
\eta_{\mathrm{el}}=\frac{I_{m} V_{m}}{A G}+\mu\left(T_{\mathrm{pv}}-T_{\mathrm{ref}}\right),
$$

where $I_{m}$ and $V_{m}$ are the current and voltage of PV module at maximum power point, $T_{\text {ref }}$ is reference temperature taken as $25^{\circ} \mathrm{C}, A$ is area of the cell $\left(\mathrm{m}^{2}\right)$, and $\mu$ is the temperature coefficient of PV efficiency at reference conditions (normally a negative quantity taken as 0.0045$)$, while, $T_{\mathrm{pv}}$ has been determined by [22] in an expression universally applicable for standard pc-Si PV modules in terms of ambient temperature $T_{a}$ as

$$
T_{\mathrm{pv}}=30+0.0175(G-30)+1.14\left(T_{a}-25\right) .
$$

However, $T_{\mathrm{pv}}$ is equal to $T_{4}$ and $T_{3}$ for $\mathrm{PV} / \mathrm{T}$ and VIPV/T modules, respectively, from Figure 3.

According to $[1,8,21]$, among other authors, the universally accepted expression for overall efficiency of a PV/T system is therefore the sum total of the electrical and thermal efficiencies expressed as

$$
\eta_{\mathrm{O}}=\eta_{\mathrm{th}}+\eta_{\mathrm{el}}
$$

The VIPV/T collector performance is also characterised using overall exergy efficiency, solar fraction, and primary energy saving efficiencies. The overall exergy efficiency encompasses thermal and electric energy quality difference by converting low quality heat energy into the comparable high quality electrical energy using the theory of Carnot cycle. Therefore, the overall exergy efficiency $\xi_{o}$ is expressed as the sum total of the thermal and electrical efficiencies expressed by [23] as

$$
\xi_{\mathrm{O}}=\eta_{C} \eta_{\mathrm{th}}+\eta_{\mathrm{el}}
$$

where $\eta_{C}$ is the ideal Carnot efficiency according to [24-28] and is given by

$$
\eta_{C}=1-\frac{T_{a}}{T_{o}}
$$

The solar fraction is the ratio of primary energy saving that a PV/T system can obtain to the overall energy demand [10], simply put as the total energy demand covered by solar energy expressed as

$$
f=\frac{1}{2}\left(\frac{Q_{L, t}-Q_{\mathrm{Aux}, t}}{Q_{L, t}}+\frac{Q_{L, e}-Q_{\mathrm{Aux}, e}}{Q_{L, e}}\right),
$$

where $Q_{L, t}$ and $Q_{\text {Aux }, t}$ are the overall thermal load and auxiliary heat required, respectively; $Q_{L, e}$ and $Q_{\text {Aux }, e}$ are the total electrical load and auxiliary electricity needed, respectively.
The principle of primary energy saving efficiency $\eta_{s}$ was introduced by [29] as a parameter that takes into account energy quality difference between heat and electricity expressed as

$$
\eta_{s}=\frac{\eta_{\mathrm{el}}}{\eta_{\mathrm{th}}+\eta_{\text {pgen }}}
$$

where $\eta_{\text {pgen }}$ is the electrical power generation efficiency for a conventional power plant, usually considered to be 0.38 .

\section{The Model Simulation}

The TRNSYS engine (Kernel) reads and processes the input file, solves the system iteratively, determines convergence, and plots the system variable. It is then possible to correlate the simulated and experimental results. This process involves a number of utilities which determines thermophysical properties, invert matrices, and interpolation of external data files where necessary. A simulation model consisting of the system parameters, input variables, performance measures functional relationships, and outputs is developed. The details of the simulation process control, time step, and time range are defined in the global info window via the control cards icon. The time step of each component reaction is defined for a detailed representation of the whole system.

The convergence test is first conducted over a range of time steps, for example, $1,0.5,0.42,0.25,0.17,0.08,0.017$, and 0.0083 hours, respectively. During these times, the results are checked and noted for the respective changes. It is observed that when reducing the time step below 0.25 hours ( 15 mins) there is no significant changes in results and therefore they are considered for the simulation study. The simulation is run in time step of 0.25 hours ( 15 minutes) and integrated to daily and annual proportions to give the prospective projections of actual performance of the VIPV/T system, since the simulation time step considered is in the order of a few seconds to several hours which gives an output in the medium-term range. Therefore, a simulation run of daily cycle or 24 hours is considered appropriate for the system analysis. For purposes of comparison with the experimental results, simulation time range considered was from 07:30 to 17:30 hours.

The accuracy of the simulation relies on the mathematical definitions of the TRNSYS types used in the model whose performances are further assumed to be optimised by selecting the appropriate simulation parameters (inputs and desired outputs) before running the simulation. To simplify the simulation, only one-dimensional heat transfer flow regime is considered for the collector. Components' behaviour lasting for milliseconds is not taken into account and heat losses from the edges and back surface are considered negligible.

The components are defined by sets of mathematical expressions in the form of algebraic and differential equations solved using successive substitution (solver 0 ) when the simulation runs are performed. The solver allows for calculation of outputs from given inputs for each unit and then passes them over as inputs to the units that follow as long as there is 

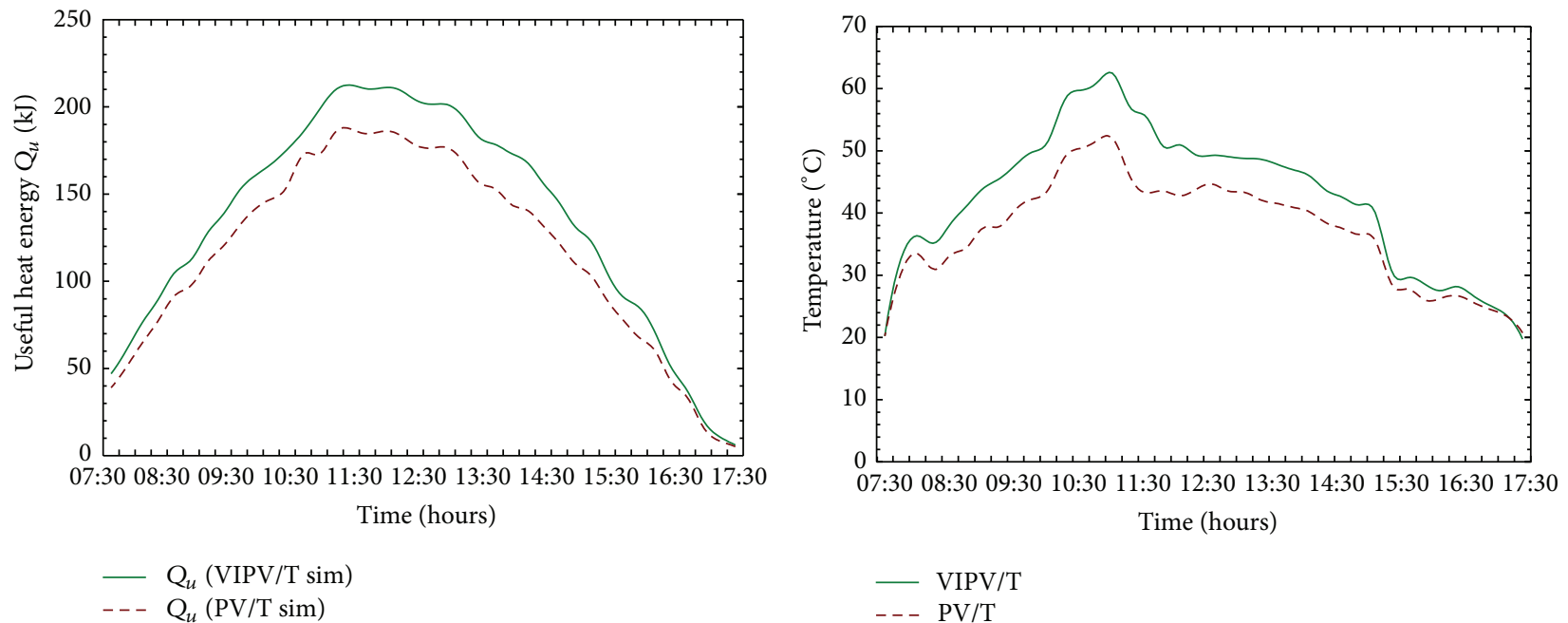

$\begin{array}{ll}- & Q_{u}(\mathrm{VIPV} / \mathrm{T} \operatorname{sim}) \\ --- & Q_{u}(\mathrm{PV} / \mathrm{T} \operatorname{sim})\end{array}$

(b) Outlet water temperature

(a) Useful heat $Q_{u}$

$-{ }^{-}$PV/T

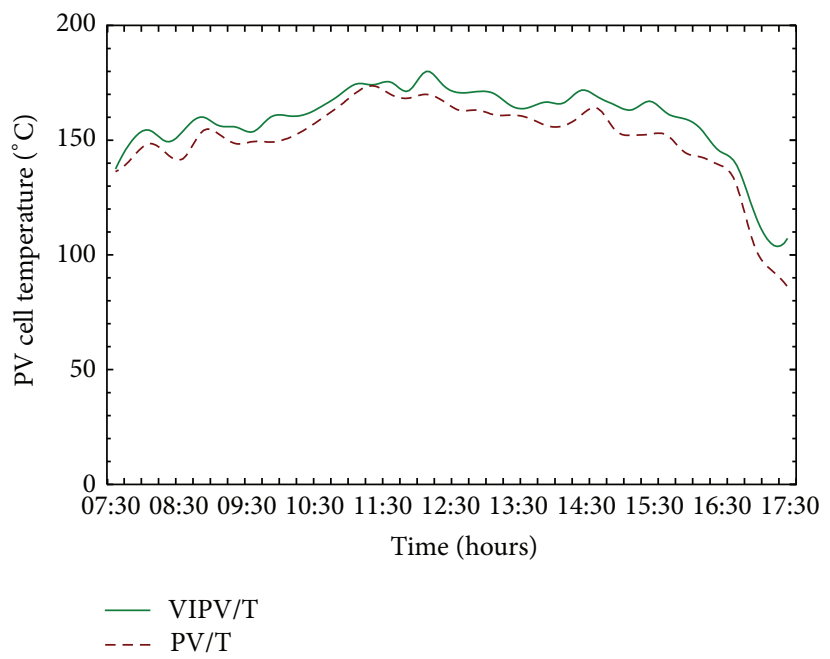

(c) PV cell surface temperature

FIGURE 4: The variation of useful heat, outlet water, and PV cell average surface temperatures as a function of time of the day.

no convergence but becomes tricky as the system approaches little or no capacitance in rapidly changing discrete states. These challenges are overcome by defining and increasing the number of iterations in the algorithm. The successive solution and modular strategy approach applied in this simulation ensures solution of the larger problem by solving several small subsystem problems, thus providing high degree of flexibility.

\section{Simulation Results and Discussion}

The performance of the VIPV/T collector is evaluated in terms of thermal and electrical energy yields and efficiencies. The variation of global solar radiation and ambient temperature for a typical meteorological year of Durban, South Africa, is used as an input parameter for this purpose. Very interesting results have been obtained, analysed, and discussed both in daily and in annual intervals.

5.1. Daily Performance Analysis. To provide a basis for comparison with experimental results, the daily simulation studies are conducted for 22/08/2014 on which the experimental analysis is based.

5.1.1. Thermal Energy. The variation of useful energy obtained from the VIPV/T and PV/T during the day under analysis is shown in Figure 4(a). It is observed that VIPV/T produces $16.5 \%$ more useful energy on average, compared to that of $\mathrm{PV} / \mathrm{T}$. In addition, the variation of water temperature with time of the day is also presented in Figure 4(b). An increase in hot water temperature of $12.9 \%$ is realised. The difference is attributed to reduced convective losses via the top of the collector and heat retention property of the vacuum insulation layer. An average hot water temperature of about $40^{\circ} \mathrm{C}$ is considered adequate for domestic applications such as hot water sanitation, bathing, washing among other activities according to [2]. The average water temperature attained for this day is $42^{\circ} \mathrm{C}$ for VIPV/T spanning over 4 hours, which is within acceptable range. Hence the system can satisfy the hot water needs of an eight persons residence without auxiliary heating on a sunny day. The maximum 


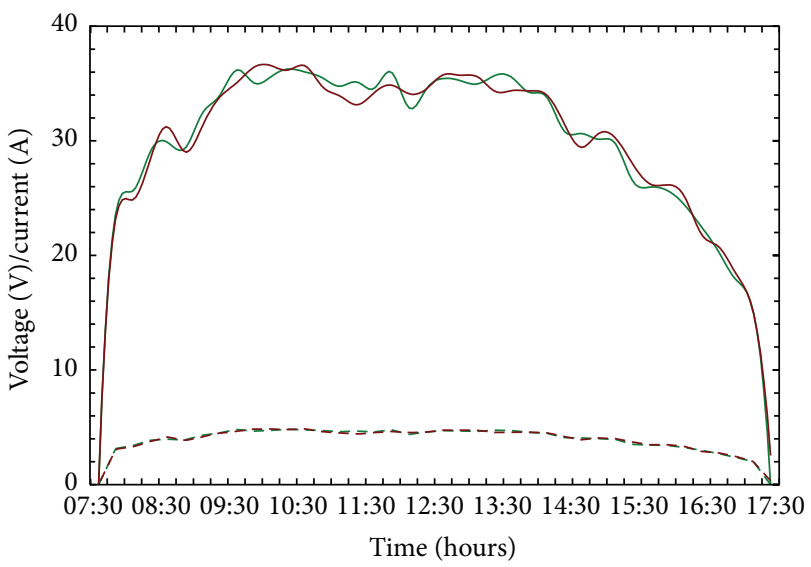

$\begin{array}{ll}\text { - Voltage }(\mathrm{VIPV} / \mathrm{T}) & \text { - Voltage }(\mathrm{PV} / \mathrm{T}) \\ -- \text { Current }(\mathrm{VIPV} / \mathrm{T}) & --- \text { Current }(\mathrm{PV} / \mathrm{T})\end{array}$

(a) The voltage and current

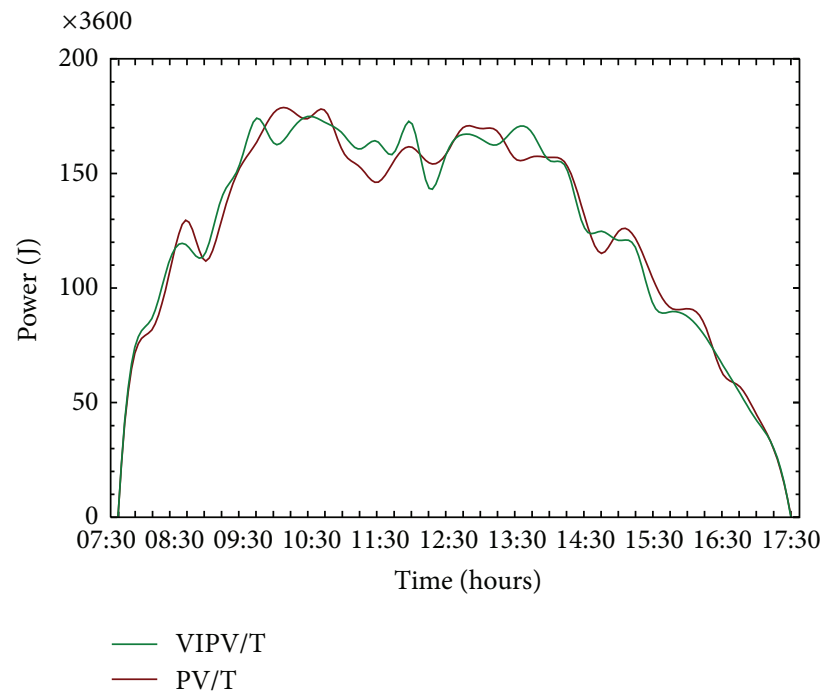

(b) Electrical power yield

FIGURE 5: The variation of voltage, current, and electrical power yield as a function of time of the day.

daily outlet water temperatures varied recorded were $51.82^{\circ} \mathrm{C}$ and $62.31^{\circ} \mathrm{C}$ for PV/T and VIPV/T respectively.

The variation of $\mathrm{PV}$ cell temperatures are shown in Figure 4(c). High PV cell temperature is realised due to the fact that the absorber-tube configuration used in this case is of header-riser type in which heat transfer is limited to the contact surface points only. There is likelihood of temperature build-up in the gaps between the tubes due to vacuum insulation. However, this temperature build-up could be reduced by varying the fluid mass flow rate as well as using the channel type absorber configuration. It is observed that VIPV/T module generates an average of 5.4\% more thermal energy compared to the PV/T counterpart. Additionally, thermal peak points occur at 12:00 and 11:30 hours for VIPV/T and PV/T, respectively. A peak time lag of 30 minutes is due to reduced losses and prolonged heat retention times resulting in marginal reduction in electrical efficiency as captured in the next section.

5.1.2. Electrical Energy. Figure 5(a) gives the daily variations of the voltage and current outputs from the VIPV/T and $\mathrm{PV} / \mathrm{T}$ collectors. From the voltages and currents obtained, the electrical power is calculated and values corresponding to the respective data points are plotted as shown in Figure 5(b). Of the total power generated from the two modules during the day under analysis, $50.2 \%$ is by VIPV/T and $49.8 \%$ is by $\mathrm{PV} / \mathrm{T}$ system. An increase of $0.03 \%$ on power generated is realised in favour of VIPV/T, a magnitude of which is negligibly small compared to the change realised in thermal energy.

5.1.3. Efficiencies. It is important to operate the PV unit at its near maximum efficiency as possible by cooling. The cooling mechanism constitutes the thermal unit which must also operate efficiently to supply the heating loads. The efficiencies for the hybrid VIPV/T in comparison to the PV/T are evaluated and hourly results plotted as shown in Figure 6(a). The VIPV/T has shown an improvement in daily average thermal efficiency by $16.8 \%$ over the $\mathrm{PV} / \mathrm{T}$ counterpart, whereas individual values are evaluated to be $15.74 \%$ and $13.5 \%$, respectively. This increase is attributed to the inclusion of the vacuum insulation layer. However, this figure can go up or down depending on the geometrical characteristics of the vacuum envelop and prevailing irradiation of the day and region.

The mean daily electrical efficiencies obtained are 9.75\% and $9.77 \%$ for VIPV/T and PV/T, respectively, indicating a reduction of $0.02 \%$. Even though the decrease is negligibly small compared to the increase in thermal efficiency, there is an indication of more reductions with higher PV cell temperature build-up associated with the VIPV/T which may require stringent controls in the long-term exposure to solar radiation. Electrical efficiency is seen to be decreasing with increase in average cell temperatures and the converse is also true, subject to the prevailing varying solar radiation levels. For broader performance characterisation of the system, the overall exergy efficiency and primary energy saving efficiencies are also evaluated to support the respective energy efficiencies. Using the expression given in (37), the overall exergy efficiency is evaluated for both systems as a function of Carnot efficiency as shown in Figure 6(b). The VIPV/T exhibits a mean exergy efficiency of $18.24 \%$, while that of $\mathrm{PV} / \mathrm{T}$ is $16.56 \%$, giving a mean improvement of $10.14 \%$ in favour of VIPV/T. Likewise, the average primary energy saving efficiencies decreased by $4.15 \%$ for VIPV/T at $19.63 \%$ compared to $\mathrm{PV} / \mathrm{T}$ at $20.48 \%$. This decrease is due to the increase in thermal efficiency which is the denominator. The individual mean Carnot efficiencies of $47.86 \%$ and $42.96 \%$ were obtained for VIPV/T and PV/T, respectively. A conventional energy power plant generation efficiency minimum of $0.38 \%$ is assumed in the calculation to give the minimum possible indication of performance improvement.

The individual overall efficiencies are $25.49 \%$ and $23.3 \%$ for VIPV/T and PV/T, respectively. The overall efficiency which is the sum of the electrical and thermal efficiencies is 


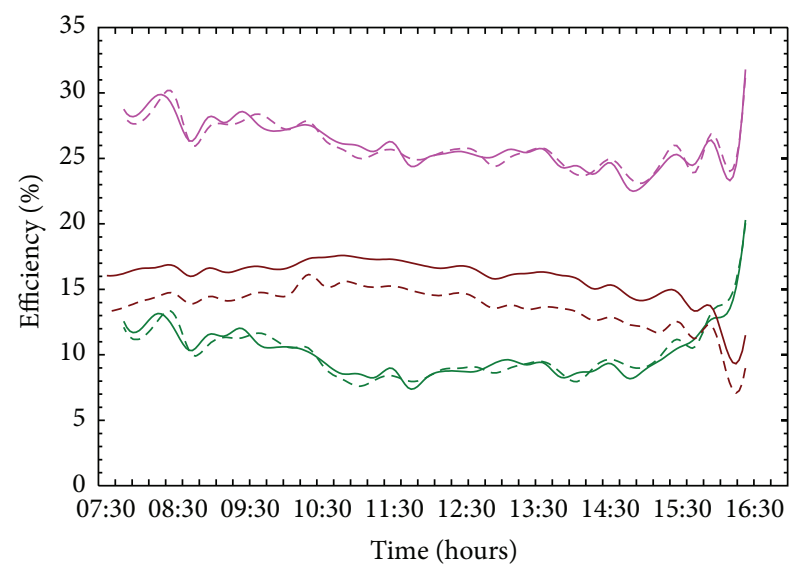

$$
\begin{array}{lll}
- & \eta_{\text {th }}(\mathrm{VIPV} / \mathrm{T}) \operatorname{sim} & --\eta_{\text {th }}(\mathrm{PV} / \mathrm{T}) \operatorname{sim} \\
-\eta_{\mathrm{el}}(\mathrm{VIPV} / \mathrm{T}) \operatorname{sim} & ---\eta_{\mathrm{el}}(\mathrm{PV} / \mathrm{T}) \operatorname{sim} \\
-\eta_{\mathrm{O}}(\mathrm{VIPV} / \mathrm{T}) \operatorname{sim} & ---\eta_{\mathrm{O}}(\mathrm{PV} / \mathrm{T}) \operatorname{sim}
\end{array}
$$

(a) Thermal, electrical, and overall efficiencies

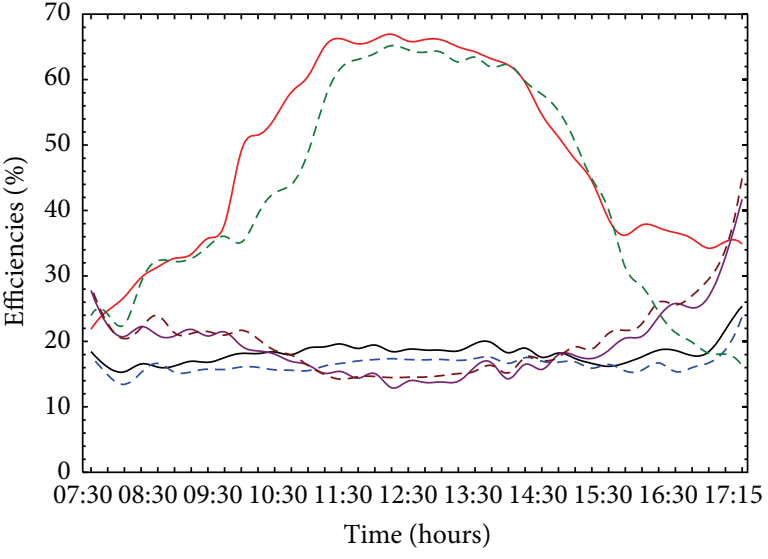

$\begin{array}{ll}\eta_{\mathrm{ex}}(\mathrm{VIPV} / \mathrm{T}) & ---\eta_{\mathrm{ex}}(\mathrm{PV} / \mathrm{T}) \\ -\eta_{C}(\mathrm{VIPV} / \mathrm{T}) & ---\eta_{C}(\mathrm{PV} / \mathrm{T}) \\ -\eta_{s}(\mathrm{VIPV} / \mathrm{T}) & ---\eta_{s}(\mathrm{PV} / \mathrm{T})\end{array}$

(b) Exergy and primary energy saving efficiencies

Figure 6: The variation efficiencies as a function of time of the day.

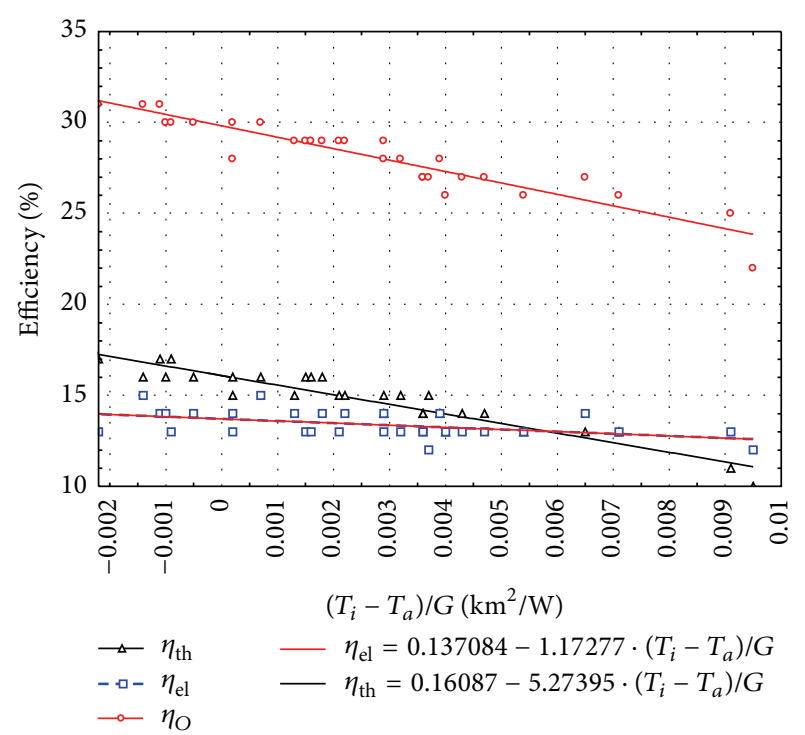

Figure 7: The variation of efficiencies as a function of $\left(T_{i}-T_{a}\right) / G$.

found to improve by $9.51 \%$ in favour of the VIPV/T system due to the higher thermal output compared to the PV/T. The variation of thermal, electrical, and overall efficiencies with respect to $\left(T_{i}-T_{a}\right) / G$ is shown in Figure 7 .

5.1.4. Effect of the Vacuum Insulation. In the PV/T system configuration, air space is applied as an insulator between the glazing and the PV cells. In stagnant air, heat transfer is by radiation through gas; however, when the air is set in motion, convective mode of heat transfer sets in, replacing conduction, the effect of which results in higher heat transfer.

From the approach and findings of this study, the vacuum envelop has been introduced in place of air layer as an insulation against the heat losses through the top of flat-plate $\mathrm{PV} / \mathrm{T}$. The overall effect is found to be convection suppression thus limiting heat loss to the radiative mode. This option results in an increase in thermal efficiency by $9.51 \%$, while electrical efficiency negligibly reduced by $0.02 \%$. This shows a huge positive difference relative to the former, an indication that there is a likelihood of electrical efficiency being unaffected. The PV glass encapsulation has also been removed, since there is no chance of cell degradation due to direct air contact. Additionally, the optical performance is improved by eliminating the extra reflections by the encapsulation glass. However, the negligible indication of reduction in electrical efficiency is seriously noted, since it could escalate further depending on the prevailing meteorological conditions of the location and period of exposure; therefore high levels of control should be put in place to ensure that PV temperatures are not raised. This fact prompts for low flow conditions in the range of 6-15 l/hm ${ }^{2}$ edge and back losses remained the same and are not considered.

5.2. Annual Performance Analysis. To predict the long-term behaviour of the VIPV/T module under varying seasonal climatic conditions, an annual simulation study is done in terms of energy outputs and efficiencies (no comparisons to PV/T). The annual energy outputs are shown in Figure 8(a), from which it can be seen that the VIPV/T module is subjected to a total annual solar irradiation $\left(G_{\text {coll }}\right)$ of $6590.26 \mathrm{MJ}$. The useful heat energy output $\left(Q_{\mathrm{uColl}}\right)$ of the module is found to vary from $386.33 \mathrm{~kJ}$ during the winter month of June to $673.65 \mathrm{~kJ}$ during the summer month of January. However, the total annual output is $6092.03 \mathrm{~kJ}$. The actual heat energy $\left(Q_{\mathrm{DHW}}\right)$ transferred to hot water is in the range of $528.3 \mathrm{~kJ}$ and $380.97 \mathrm{~kJ}$ also corresponding to the months of January and June, respectively. The total and average outputs for the year are $40.89 \mathrm{MJ}$ and $340.76 \mathrm{~kJ}$, respectively.

On the other hand, based on the hot water loads considered for a domestic set-up of 8 persons, a total of $34.81 \mathrm{MJ}$ is required for use during the nonsunshine or low radiation periods. However, this figure may increase with no solar 


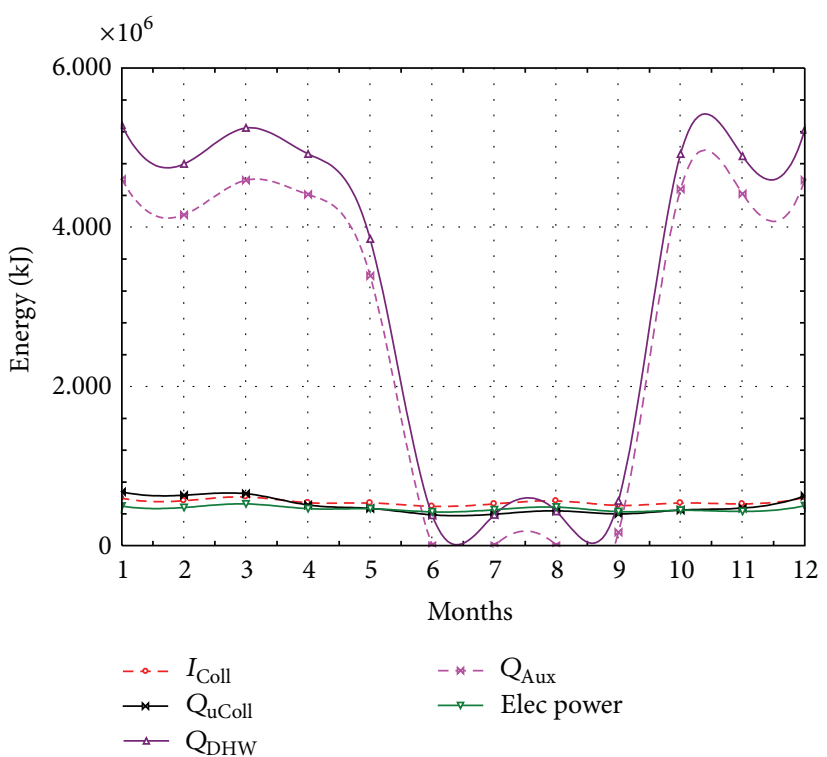

(a) Energy generated

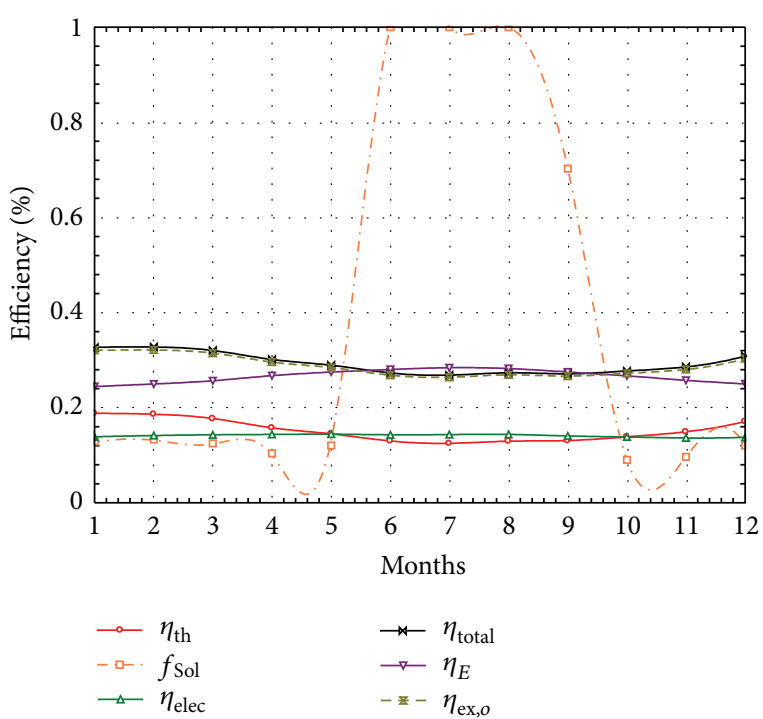

(b) Efficiencies

FIGURE 8: The global annual variation of energy yield and efficiencies with time.

energy intervention as demonstrated by the solar fraction. Based on the electrical loads considered for simulation, the annual electrical energy yield for the VIPV/T is found to be in the range of $1524.132 \mathrm{~kJ}$ and $1887.696 \mathrm{~kJ}$; however, the total power generated for the year is $20,091.816 \mathrm{~kJ}$. Considering the peak demand of $3060 \mathrm{~kJ}$ for the residence under consideration, this energy is found to be adequate. Even though, in some instances, it goes lower than the required level, this challenge may be met by adding more storage hours to supply the deficit or consider supplementing with grid power if available at that instance.

Figure 8(b) shows the variation of annual efficiencies. It is observed that the mean thermal, electrical, exergy, and primary energy saving efficiencies were found to be $18 \%, 11 \%$, $29 \%$, and $27 \%$, respectively. The overall energy efficiency is $29 \%$, while solar fraction is $39 \%$. Most notable is the solar fraction which approaches 100\% between June and August, as the corresponding auxiliary energy approaches zero. This is attributed to the fact that the skies are generally clear and less humid during this period allowing more direct and less diffuse radiation to reach the VIPV/T collector surface.

\section{Comparison of Simulation and Experimental Results}

The periods for comparison are based on the experimental hours between 07:30 hours and 17:30 hours of 22/08/2014. The most important performance characteristic parameters compared are thermal energy output and efficiencies.

6.1. Comparison of Thermal Energy Outputs. The comparison of simulated and experimental useful heat is shown in Figure 9(a). It is observed that there is an average variation of about $1.22 \%$. Individually, simulated and experimental values differ by $1.53 \%$ for VIPV/T and PV/T, respectively.
The variation of simulated and measured outlet water temperatures is plotted in Figure 9(b). Model predicts the outlet temperature with a variance of $0.4 \%$ and $0.7 \%$ for $\mathrm{VIPV} / \mathrm{T}$ and $\mathrm{PV} / \mathrm{T}$ systems, respectively, in comparison to the experimental data.

Figure 9(c) shows the variation of simulated and experimental average PV cell temperatures for the hybrid VIPV/T as well as the PV/T collectors. The simulation tallied with the experimental results to the degree of $0.8 \%$ and $1.05 \%$ for the VIPV/T and PV/T, respectively.

6.2. Comparison of Efficiencies. The efficiencies for hybrid VIPV/T module obtained by simulation and experiment are compared and plotted in Figure 10(a). Using the experimental results as the basis of comparison, the percentage difference between experimental and simulated values can be obtained as follows:

$$
\left(\frac{\eta_{\text {Exp }}-\eta_{\text {Sim }}}{\eta_{\operatorname{Exp}}}\right) \times 100 \%
$$

The difference between the simulated (dashed lines) and the experimental thermal, electrical, and overall efficiencies is $1.05 \%, 1.29 \%$, and $3.57 \%$, respectively.

Figure 10(b) presents the variation of exergy and energy saving efficiencies for the hybrid VIPV/T collector. As can be seen, there is a narrow gap of $3.6 \%$ and $2.8 \%$ between the simulated (dashed lines) and experimental values for exergy and energy saving efficiencies, respectively.

It can be noted that, in all the cases, the simulated results compared to the experimental data with a variance of less than $4 \%$. With this performance, it can be concluded that the model can be used to accurately predict the performance of a VIPV/T, especially in the case where such kind of technology has not been used. 


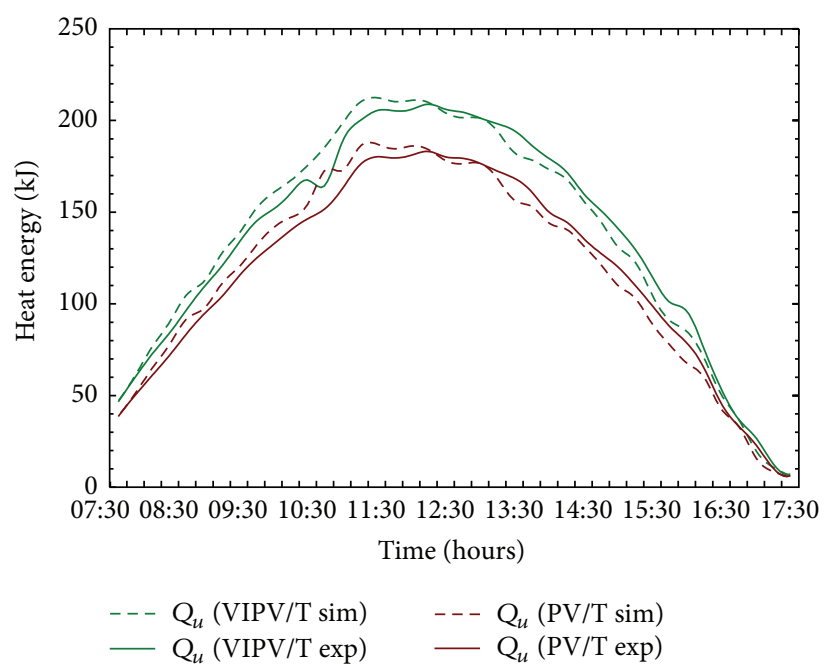

(a) Useful heat energy

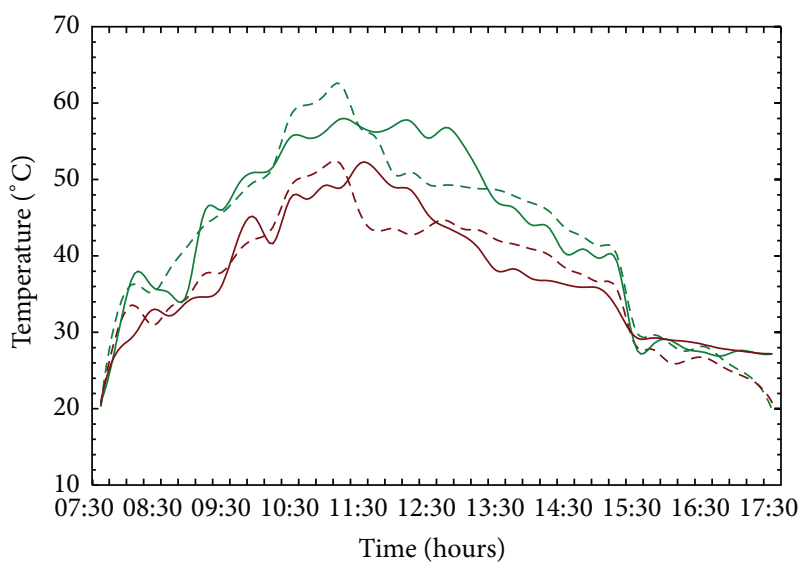

$\begin{array}{ll}--T_{o}(\mathrm{VIPV} / \mathrm{T} \operatorname{sim}) & -T_{o}(\mathrm{VIPV} / \mathrm{T} \exp ) \\ ---T_{o}(\mathrm{PV} / \mathrm{T} \operatorname{sim}) & -\mathrm{T}_{o}(\mathrm{PV} / \mathrm{T} \exp )\end{array}$

(b) Outlet water temperatures

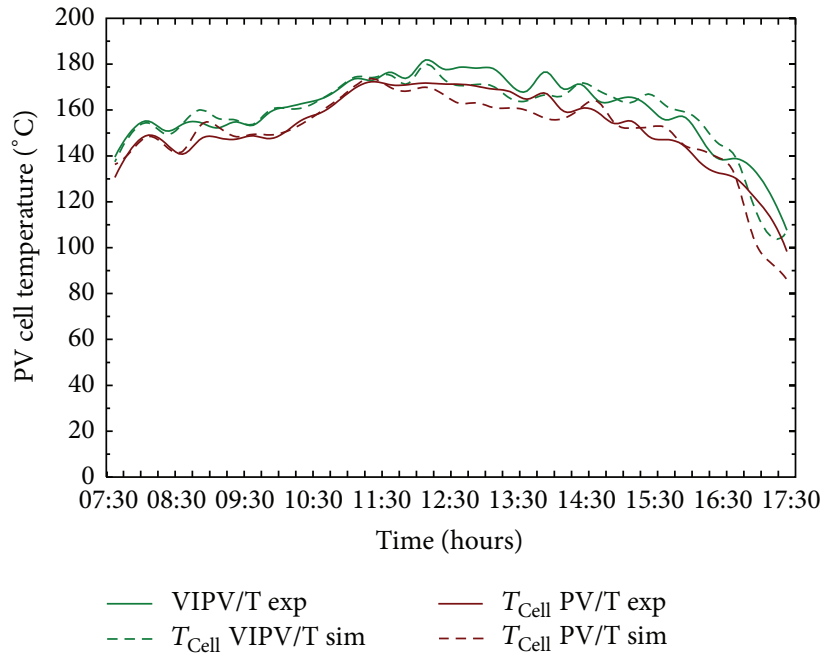

(c) Average cell temperatures

Figure 9: The variation of simulated and experimental temperatures with time.

\section{Conclusions}

This study has demonstrated that hybrid VIPV/T module presents superior thermal characteristics compared to conventional $\mathrm{PV} / \mathrm{T}$ with air insulation layer. From the results of the daily simulation, it is ascertained that the inclusion of the vacuum insulation has given rise to improved thermal efficiency by $16.8 \%$; correspondingly, the useful heat generated also increased by $16.8 \%$. The electrical efficiency marginally reduced by $0.02 \%$ due to increased average PV cell temperatures of about $5.4 \%$. Most importantly, the overall efficiency improved by $9.51 \%$ in addition to increase of $10.14 \%$ in overall exergy and decrease of $4.15 \%$ in primary energy saving efficiencies, respectively. In the annual simulation scale, the hybrid VIPV/T has attained average values of $18 \%, 11 \%, 29 \%$, and $27 \%$ of thermal, electrical, exergy, and primary energy saving efficiencies, respectively. The overall efficiency is $29 \%$, while annual solar fraction of $39 \%$ is also registered.
The results of the simulation and experimental studies are substantively compared and analysed with relevant observations. The deviations between the respective simulated and experimental results were shown to vary in the range of $0.4 \%$ to $3.6 \%$. These are attributed to the various assumptions made for simplification of the simulation. Additionally, the major contributor to the deviations is the difference between the predicted (TMY weather data) and the actual (measured weather data) files used for simulation and experiment, respectively. However, these variations are well within the acceptable limits of 5\%. Therefore, the simulation and experimental results tallied satisfactorily well to show the functionality, accuracy, and validity of the model developed.

The analysis presented in this work is based on measurements for one day; however, in order to establish a trend of systems' behaviour under varying weather conditions, measurements for prolonged periods may be conducted to cover the thermal behaviour during night hours. Based on the results obtained from this study, the VIPV/T offers 


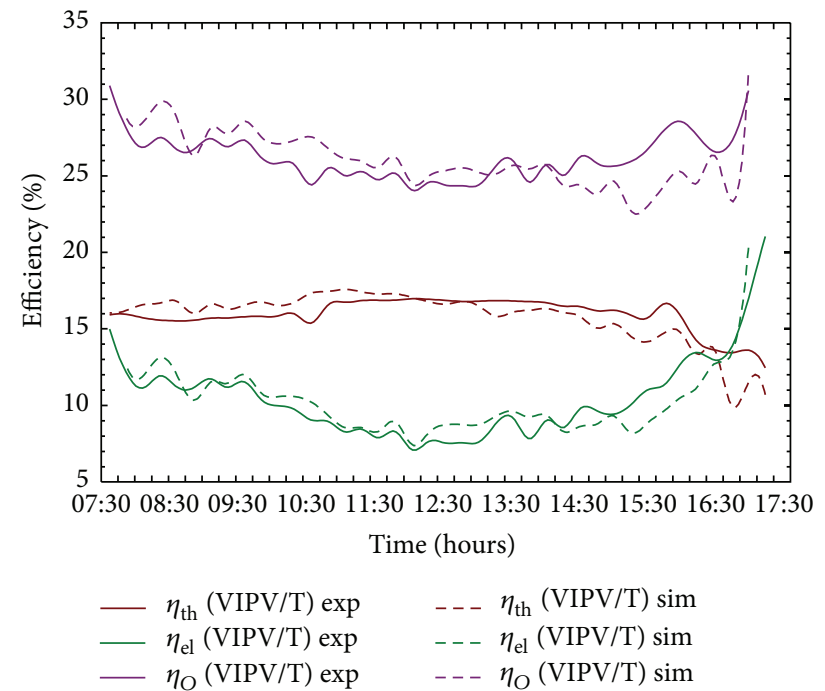

(a) Thermal, electrical and, overall

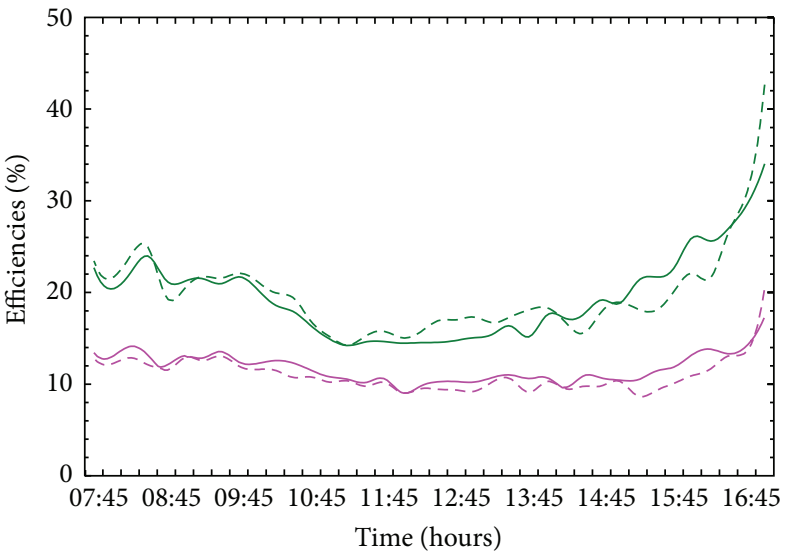

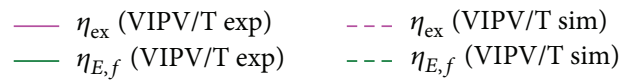

(b) Exergy and primary energy saving

FIGURE 10: The variation of simulated and experimental efficiencies for VIPV/T module.

an improved thermal energy output as well as efficiencies. However, it has shown a possibility of elevated PV cell temperatures, which results in reduced electrical efficiencies. In order to check these temperatures, the use of thermostatic controls is recommended.

\section{Nomenclature}

A : Area of the collector $\left(\mathrm{m}^{2}\right)$

I: $\quad$ Current (A)

G: Solar irradiance $\left(\mathrm{W} / \mathrm{m}^{2}\right)$

M: Mass of collector components $(\mathrm{kg})$

T: $\quad$ Temperature $\left({ }^{\circ} \mathrm{C}\right)$

$t$ : Time from midnight (hours)

$V:$ Voltage (V)

Q: Heat gain $(\mathrm{kJ})$

q: Heat flux $(\mathrm{kJ} / \mathrm{s})$

$F: \quad$ View factor $(-)$

$C_{p}$ : Specific heat capacity of the fluid $(\mathrm{kJ} / \mathrm{kgK})$

$\dot{m}$ : Fluid mass flow rate $(\mathrm{kg} / \mathrm{s})$

$\eta$ : $\quad$ Efficiency $(-)$

$\mathrm{Nu}$ : Nusselt number (-)

$U:$ Overall heat loss coefficient $\left(\mathrm{W} / \mathrm{m}^{2} \mathrm{~K}\right)$

Pr: Prandtl number $(-)$

Re: Reynold's number (-)

$v$ : Wind velocity $(\mathrm{m} / \mathrm{s})$

$\alpha$ : Absorptance (-)

g: Acceleration due to gravity $\left(\mathrm{m} / \mathrm{s}^{2}\right)$

$l$ : $\quad$ Length $(\mathrm{m})$

$R:$ Thermal resistance $\left(\mathrm{Km}^{2} / \mathrm{W}\right)$

$f$ : Solar fraction $(-)$

$\gamma$ : $\quad$ Bond thickness $(\mathrm{m})$

$\beta$ : Collector inclination angle $\left({ }^{\circ}\right)$

$\rho: \quad$ Density $\left(\mathrm{kg} / \mathrm{m}^{3}\right)$

$\eta$ : $\quad$ Efficiency (-)

$\varepsilon$ : $\quad$ Emittance $(-)$

$\xi: \quad$ Exergy efficiency $(-)$ $\delta$ : Plate thickness (m)

$\sigma$ : Stefan-Boltzmann constant $\left(\mathrm{W} / \mathrm{m}^{2} \mathrm{~K}^{4}\right)$

$\mu$ : Temperature coefficient at reference conditions (-)

$\tau$ : Transmittance $(-)$

$\omega$ : Thermal diffusivity $\left(\mathrm{m}^{2} / \mathrm{s}\right)$.

Subscripts

$\begin{array}{ll}a: & \text { Ambient } \\ \text { abs: } & \text { Absorber } \\ \text { Aux: } & \text { Auxiliary }\end{array}$

DHW: Domestic hot water

$b$ : $\quad$ Bond

C: $\quad$ Carnot

c: Collector

dp: Dew point

el: Electrical

g: Glass

grd: Ground

$i$ : $\quad$ Inlet

$L$, el: Load, electrical

$L$, th: Load, thermal

loss: Energy lost to the surrounding

max: Maximum

$o$ : Outlet

O: Overall

pgen: Power generation

pv: Photovoltaic

pvg: PV glazing

ref: Reference

$s: \quad$ Saving

sky: Sky 


$$
\begin{array}{ll}
\text { th: } & \text { Thermal } \\
t: & \text { Top } \\
u: & \text { Useful } \\
\text { uColl: } & \text { Useful energy of collector } \\
v: & \text { Kinematic viscosity }\left(\mathrm{m}^{2} / \mathrm{s}\right) .
\end{array}
$$

\section{Competing Interests}

The authors of this paper declare that there are no competing interests and that this is just a pure academic research work with no financial gains derived from the TRNSYS software company.

\section{Acknowledgments}

The authors wish to acknowledge the financial support offered by the Centre for Postgraduate Studies (CEPS) and laboratory materials provided by Green Energy Solutions (GES) research group of the University of KwaZulu-Natal.

\section{References}

[1] R. M. da Silva and J. L. M. Fernandes, "Hybrid photovoltaic/ thermal (PV/T) solar systems simulation with simulink/matlab," Solar Energy, vol. 84, no. 12, pp. 1985-1996, 2010.

[2] S. Kalogirou, Solar Energy Engineering: Processes and Systems, Academic Press, Elsevier, Amsterdam, The Netherlands, 2009.

[3] H. A. Zondag, D. W. De Vries, W. G. J. Van Helden, R. J. C. Van Zolingen, and A. A. Van Steenhoven, "The thermal and electrical yield of a PV-thermal collector," Solar Energy, vol. 72, no. 2, pp. 113-128, 2002.

[4] H. A. Zondag, D. W. de Vries, W. G. J. van Helden, R. J. C. van Zolingen, and A. A. van Steenhoven, "The yield of different combined PV-thermal collector designs," Solar Energy, vol. 74, no. 3, pp. 253-269, 2003.

[5] G. Tiwari and S. Dubey, "Thermal modelling of hybrid photovoltaic/thermal (PV/T) systems," in Fundamentals of Photovoltaic Modules and their Applications, chapter 7, pp. 174-256, The Royal Society of Chemestry, London, UK, 2009.

[6] Y. Tripanagnostopoulos, T. Nousia, M. Souliotis, and P. Yianoulis, "Hybrid photovoltaic/thermal solar systems," Solar Energy, vol. 72, no. 3, pp. 217-234, 2002.

[7] M. J. Elswijk, M. J. M. Jong, K. J. Strootman, J. N. C. Braakman, E. T. N. de Lange, and W. F. Smit, "Photovoltaic/thermal collectors in large solar thermal systems," in Proceedings of the 19th European PV Solar Energy Conference and Exhibition (EPSEC '04), Paris, France, June 2004.

[8] S. A. Kalogirou and Y. Tripanagnostopoulos, "Industrial application of PV/T solar energy systems," Applied Thermal Engineering, vol. 27, no. 8-9, pp. 1259-1270, 2007.

[9] M. Mattei, G. Notton, C. Cristofari, M. Muselli, and P. Poggi, "Calculation of the polycrystalline PV module temperature using a simple method of energy balance," Renewable Energy, vol. 31, no. 4, pp. 553-567, 2006.

[10] S. A. Kalogirou, "Use a TRNSYS for modelling and simulation of a hybrid pv-thermal solar system for Cyprus," Renewable Energy, vol. 23, no. 2, pp. 247-260, 2001.

[11] S. A. Kalogirou and Y. Tripanagnostopoulos, "Hybrid PV/T solar systems for domestic hot water and electricity production,"
Energy Conversion and Management, vol. 47, no. 18-19, pp. 3368$3382,2006$.

[12] R. Santbergen, C. C. M. Rindt, H. A. Zondag, and R. J. C. van Zolingen, "Detailed analysis of the energy yield of systems with covered sheet-and-tube PVT collectors," Solar Energy, vol. 84, no. 5, pp. 867-878, 2010.

[13] S. Dubey and G. N. Tiwari, "Analysis of PV/T flat plate water collectors connected in series," Solar Energy, vol. 83, no. 9, pp. 1485-1498, 2009.

[14] S. Dubey and G. N. Tiwari, "Thermal modeling of a combined system of photovoltaic thermal (PV/T) solar water heater," Solar Energy, vol. 82, no. 7, pp. 602-612, 2008.

[15] T. T. Chow, "A review on photovoltaic/thermal hybrid solar technology," Applied Energy, vol. 87, no. 2, pp. 365-379, 2010.

[16] S. Agrawal and A. Tiwari, "Experimental validation of glazed hybrid micro-channel solar cell thermal tile," Solar Energy, vol. 85, no. 11, pp. 3046-3056, 2011.

[17] J. Ji, J.-P. Lu, T.-T. Chow, W. He, and G. Pei, "A sensitivity study of a hybrid photovoltaic/thermal water-heating system with natural circulation," Applied Energy, vol. 84, no. 2, pp. 222-237, 2007.

[18] B. Sandnes and J. Rekstad, "A photovoltaic/thermal (PV/T) collector with a polymer absorber plate. Experimental study and analytical model," Solar Energy, vol. 72, no. 1, pp. 63-73, 2002.

[19] A. Y. A. Oyieke and F. L. Inambao, "Simulation and performance evaluation of a vacuum insulated hybrid solar photovoltaic/thermal powermodule for domestic applications in South Africa," TMC Academic Journal, vol. 9, no. 2, pp. 1-19, 2015.

[20] H. A. Zondag, "Flat-plate PV-thermal collectors and systems: a review," Renewable and Sustainable Energy Reviews, vol. 12, no. 4, pp. 891-959, 2008.

[21] J. A. Duffie and W. Beckman, Eds., Solar Engineering of Thermal Processes, Encyclopaedia of Mathematical Sciences, John Wiley \& Sons, Hoboken, NJ, USA, 4th edition, 2013.

[22] F. Lasnier and T. G. Ang, The Photovoltaic Engineering Handbook, Adam Higler, New York, NY, USA, 1990.

[23] A. Tiwari, S. Dubey, G. S. Sandhu, M. S. Sodha, and S. I. Anwar, "Exergy analysis of integrated photovoltaic thermal solar water heater under constant flow rate and constant collection temperature modes," Applied Energy, vol. 86, no. 12, pp. 2592-2597, 2009.

[24] B. Miroslav, S. Bosanac, I. Katic, H. Svrensen, N. Bruno, and B. Jamal, "Photovoltaic/thermal solar collectors and their potential in denmark," Final Report EFP Project 1713/00-0014, 2003.

[25] R. Saidur, G. Boroumandjazi, S. Mekhlif, and M. Jameel, "Exergy analysis of solar energy applications," Renewable and Sustainable Energy Reviews, vol. 16, no. 1, pp. 350-356, 2012.

[26] T. T. Chow, G. Pei, K. F. Fong, Z. Lin, A. L. S. Chan, and J. Ji, "Energy and exergy analysis of photovoltaic-thermal collector with and without glass cover," Applied Energy, vol. 86, no. 3, pp. 310-316, 2009.

[27] S. Agrawal and G. N. Tiwari, "Energy and exergy analysis of hybrid micro-channel photovoltaic thermal module," Solar Energy, vol. 85, no. 2, pp. 356-370, 2011.

[28] K. Vats and G. N. Tiwari, "Energy and exergy analysis of a building integrated semitransparent photovoltaic thermal (BISPVT) system," Applied Energy, vol. 96, pp. 409-416, 2012.

[29] B. J. Huang, T. H. Lin, W. C. Hung, and F. S. Sun, "Performance evaluation of solar photovoltaic/thermal systems," Solar Energy, vol. 70, no. 5, pp. 443-448, 2001. 

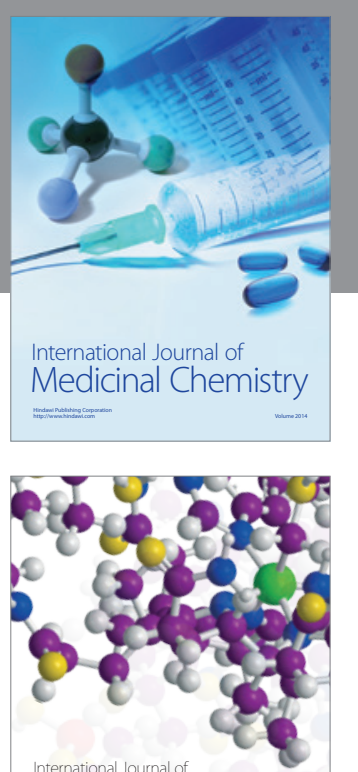

Carbohydrate Chemistry

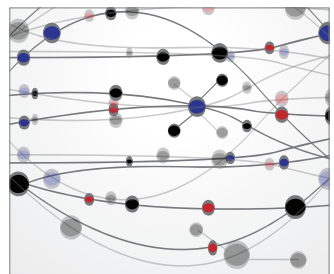

The Scientific World Journal
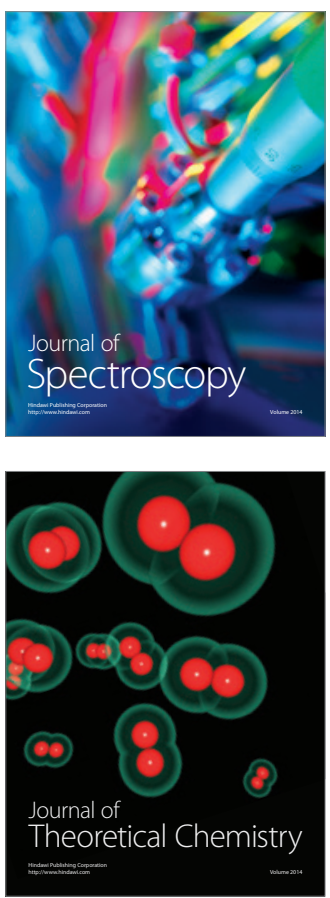
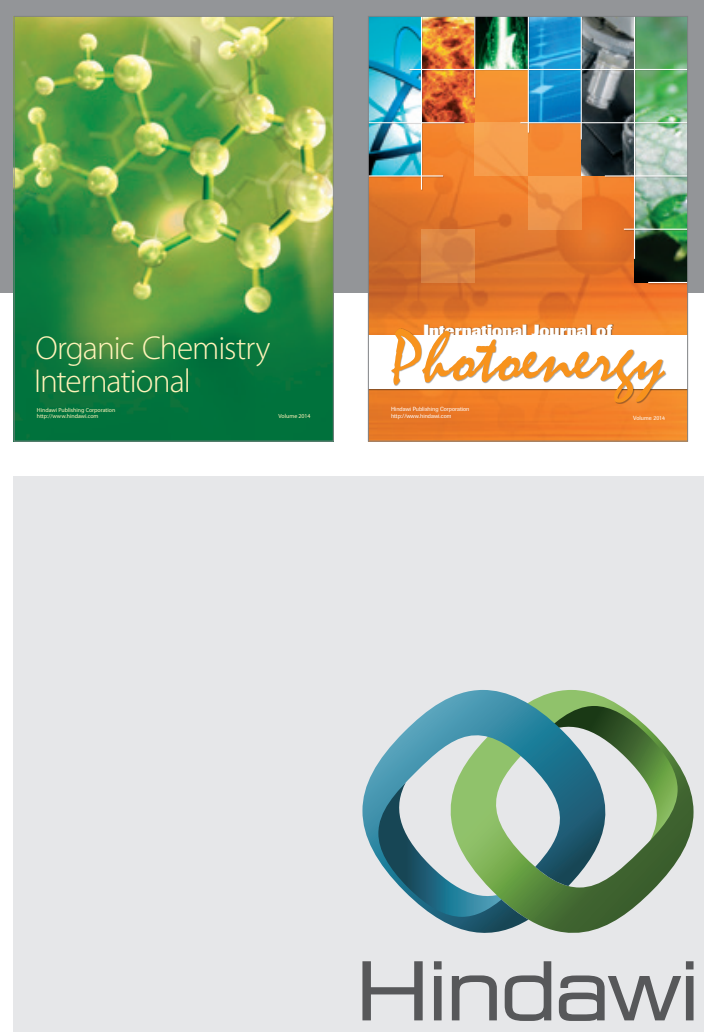

Submit your manuscripts at

http://www.hindawi.com

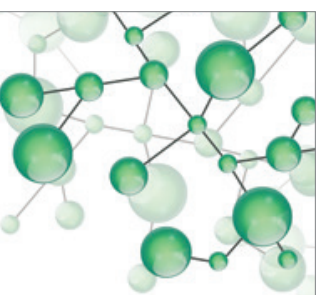

International Journal of

Inorganic Chemistry

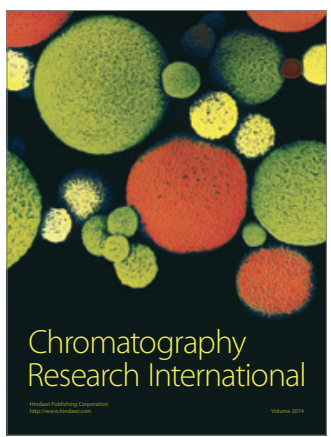

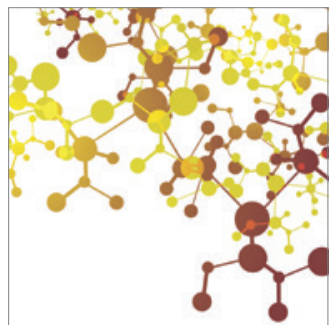

Applied Chemistry
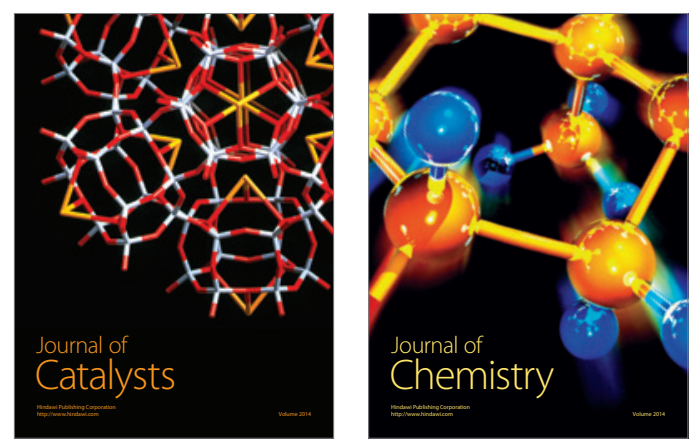
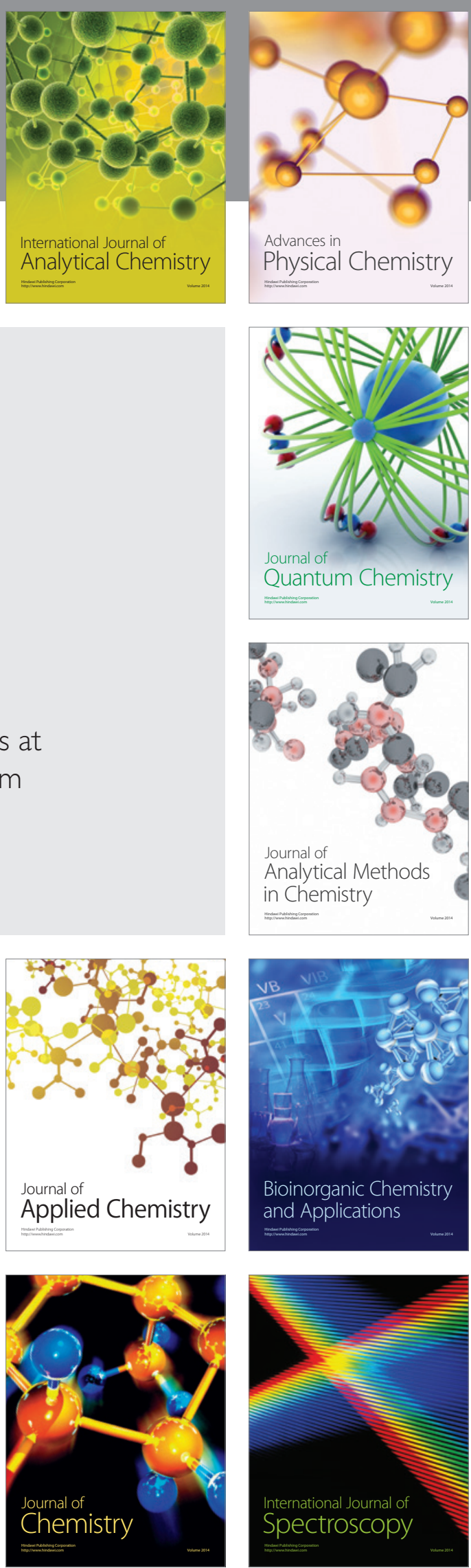